\title{
LA DEMANDA DE TEXTILES \\ DE LAS FAMILIAS CASTELLANAS A FINALES \\ DEL ANTIGUO RÉGIMEN, 1750-1850: \\ ¿AUMENTO DEL CONSUMO SIN INDUSTRIALIZACIÓN? *
}

FERNANDO CARLOS RAMOS PALENCIA

\section{RESUMEN}

En este artículo se estudia la demanda de textiles por parte de las familias castellanas de la provincia de Palencia entre 1750 y 1850 . A partir de un análisis sistemático de inventarios post mortem, se constata un aumento en el consumo de bienes textiles que afectó a todas las capas sociales ubicadas tanto en entornos urbanos como rurales. No obstante, existían una serie de límites al desarrollo de la demanda y del consumo: pervivencia de crisis de subsistencias y mortalidad, lento crecimiento demográfico, fluctuaciones en los niveles de precios agrícolas, integración de los mercados no uniforme, incremento de la masa de indigentes, excesiva concentración de la riqueza, etcétera. La existencia de estos límites incidieron en el resultado final: una revolución industriosa sin industrialización.

\section{ABSTRACT}

This article analyses the demand for textile in Castilian families between 1750 and 1850 . Through a systematic analysis of probate inventories, the results show there was a gradual increase in the demand of textiles in urban and rural families. This fact challenges the traditional interpretation about the role of internal demand in Spanish Industrial Revolution. There were however restrictions to the demand of consumer goods, such as subsistence crisis and mortality, slow demographic growth, fluctuations in agricultural prices,

* Me gustaría agradecer los comentarios y sugerencias realizados por los profesores Joaquín Cuevas, Lina Gálvez, Enrique Llopis, Joan Rosés, Jaume Torras y Bartolomé Yun, asumiendo por mi parte la total responsabilidad sobre los errores cometidos.

Revista de Historia Económica

Año XXI, 2003, N. extraordinario 
incomplete market integration, excessive concentration of wealth, etc. The existence of these restrictions conditioned the final result: an «industrious revolution» without «industrial revolution».

JEL Classification: N33, N930, R21.

En las siguientes líneas voy a tratar de aportar pruebas que demuestren si se produjo o no un crecimiento en el consumo familiar de textiles en Castilla entre 1750 y 1850 . Con tal fin utilizo distintos inventarios post mortem procedentes de las clases medias de la provincia palentina ${ }^{1}$. Obviamente, mi propósito no es contar una historia económica local o regional sobre Palencia o Castilla, sino tratar de explicar por qué disminuyó o aumentó, según sea el caso, el consumo familiar de artículos textiles en las economías preindustriales e insertar la respuesta tanto en la historiografía económica española como internacional. La cuestión clave a debatir es si existía un mercado interior, previo al proceso de industrialización español, que demandaba artículos de consumo en general y productos textiles, en particular; o, por el contrario, Castilla era una economía al borde de la subsistencia. En caso afirmativo, ¿’por qué aumentó el consumo de bienes textiles en los años finales del Antiguo Régimen? ¿Cuáles fueron las bases económicas, institucionales y sociales de dicho proceso? ¿Por qué dicho crecimiento no desembocó en un proceso de industrialización? ¿Cuál fue el papel de Castilla en la industrialización española? Las respuestas son demasiado complejas y evidentemente no pretendo dar cabida aquí a todos estos interrogantes, pero sí aportar datos que nos hagan reflexionar sobre las posibilidades de crecimiento industrial y los niveles de vida en Castilla y León, en las primeras décadas del siglo XIX, a tenor de las pautas de consumo familiar de textiles.

${ }^{1}$ En concreto he utilizado cerca de cuatrocientos inventarios post mortem en tres períodos cronológicos diferentes: $1752-1765,1785-1800$ y $1830-1840$ correspondientes a la provincia de Palencia. Obviando los problemas metodológicos asociados a dicha documentación notarial, en dichos inventarios se han considerado distintos intervalos de riqueza patrimonial, al tiempo que se han cruzado datos con la información existente en el Catastro de Ensenada. Esto se ha hecho con el objeto de reducir el sesgo hacia los patrimonios más elevados y obtener una muestra lo suficientemente representativa de la población palentina. Para mayor detalle sobre el proceso de elaboración seguido y los criterios de selección adoptados, véase $\operatorname{Ramos}$ (2001a), pp. 37-59. 


\section{LA EVOLUCIÓN DEL CONSUMO FAMILIAR DE TEXTILES: LA PROGRESIVA IMPORTANCIA DEL ALGODÓN}

En principio, parece difícil imaginar que la población castellana pudiera dedicar una parte creciente de sus ingresos hacia el consumo de bienes textiles, dado el elevado peso de los alimentos y la dieta relativamente insuficiente durante los siglos XVIII y XIX ${ }^{2}$. Sin embargo, los primeros resultados globales sobre el consumo de textiles - plasmados en el cuadro 1 apuntan a que tanto en cifras absolutas como en términos relativos se produjo, entre 1750 y 1840 , un aumento continuado en el stock de textiles. Recordemos, asimismo, que aunque desconocemos con exactitud el gasto anual (flujo) en los textiles, sí podemos intuir que el ritmo de reposición en este tipo de bienes fue mucho más acusado que en otros bienes duraderos o semiduraderos, lo cual significa que el consumo final de los textiles fue obviamente mucho más elevado de lo que se refleja en dicho cuadro. Más pormenorizadamente, se observa un significativo aumento en el número de piezas textiles por familia, las cuales pasan de 48 unidades a mediados del siglo xvII a 67 en 1830-1840. Según observamos en dicho cuadro, el grupo textil que mayor crecimiento experimentó entre 1750 y 1840 fue el vestido y calzado, que pasó de 22 piezas por familia a 34 . Dentro de la indumentaria personal los artículos textiles que mayor aumento tuvieron fueron las prendas interiores y los pañuelos. Las prendas exteriores, la partida más importante y numerosa, presentan un crecimiento relativamente moderado en 1830-1840 e incluso disminuyen en los núcleos rurales. Sorprendentemente, destaca la poca presencia de calzado y la paulatina disminución de los complementos del vestir - sombreros, corbatas, guantes, etcétera-cuando, por ejemplo, el sombrero chambergo o el de ala ancha, amén de otros tocados muy populares como las monteras, los sombreros de paja de centeno y las gorras, estuvieron presentes en casi todos los rincones de España hasta muy entrado el siglo XIX. Por lo que respecta al calzado, tal vez fuera la parte de la indumentaria más reacia a dejarse influir por las modas, de ahí que las polainas y los calzados como las abarcas, las alpargatas y las madreñas o zuecos de madera fueran dando paso muy lentamente a los zapatos, botas o botines en los inventarios post mortem. Con respecto a las piezas de cama, éstas aumentan, entre 1750 y 1840 , de 18 a 24 unidades por inventario post mortem. Más en concreto, sobresale

${ }^{2}$ Véase en este sentido los trabajos de Carasa (1987), pp. 193-195, y Simpson (1989), pp. 355-388. 
CUADRO 1

Númerò de piezas textiles por familia: Palencia, 1750-1840

\begin{tabular}{|c|c|c|c|c|c|c|c|c|c|}
\hline \multirow{2}{*}{ Artículos textiles } & \multicolumn{3}{|c|}{$1752-1765$} & \multicolumn{3}{|c|}{$1785-1800$} & \multicolumn{3}{|c|}{$1830-1840$} \\
\hline & Ciudad & Campo & TOTAL & Ciudad & Campo & TOTAL & Ciudad & Campo & TOTAL \\
\hline Prendas exteriores . & 30,52 & 12,85 & 16,62 & 35,45 & 16,69 & 20,88 & 38,53 & 15,48 & 21,07 \\
\hline 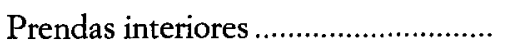 & 5,08 & 1,48 & 2,25 & 10,79 & 1,83 & 3,83 & 14,53 & 2,59 & 5,48 \\
\hline 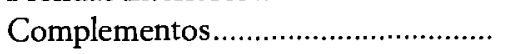 & 4,40 & 1,36 & 2,01 & 2,79 & 1,26 & 1,60 & 2,59 & 0,82 & 1,25 \\
\hline 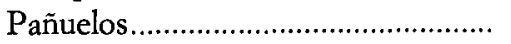 & 0,28 & 0,23 & 0,24 & 3,66 & 0,58 & 1,27 & 13,03 & 2,04 & 4,70 \\
\hline Calzado... & 1,48 & 0,93 & 1,05 & 0,76 & 1,14 & 1,05 & 1,50 & 1,22 & 1,29 \\
\hline Total vestido y calzado ............. & $\begin{array}{c}42,40 \\
(1.060)\end{array}$ & $\begin{array}{c}16,96 \\
(1.560)\end{array}$ & $\begin{array}{c}22,39 \\
(2.620)\end{array}$ & $\begin{array}{r}54,07 \\
(1.568)\end{array}$ & $\begin{array}{c}21,71 \\
(2.193)\end{array}$ & $\begin{array}{c}28,93 \\
(3.761) \\
\end{array}$ & $\begin{array}{r}70,78 \\
(2.265)\end{array}$ & $\begin{array}{c}22,24 \\
(2.224)\end{array}$ & $\begin{array}{c}34,01 \\
(4.489)\end{array}$ \\
\hline Almo & 9,00 & 2,77 & 4,10 & 9,86 & 2,57 & 4,20 & 9,69 & 3,38 & 4,91 \\
\hline 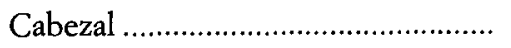 & 0,88 & 1,39 & 1,28 & 0,10 & 0,64 & 0,52 & 0,03 & 0,15 & 0,12 \\
\hline 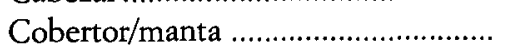 & 7,48 & 5,27 & 5,74 & 5,48 & 4,94 & 5,06 & 4,84 & 6,24 & 5,90 \\
\hline 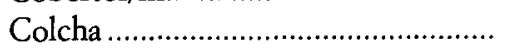 & 2,16 & 0,75 & 1,05 & 4,14 & 0,66 & 1,44 & 4,75 & 0,93 & 1,86 \\
\hline 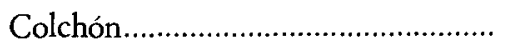 & 2,64 & 0,29 & 0,79 & 3,90 & 0,46 & 1,22 & 4,63 & 1,23 & 2,05 \\
\hline 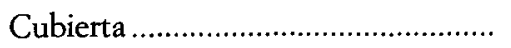 & 0,72 & 0,35 & 0,43 & 0,69 & 0,28 & 0,37 & 0,41 & 0,48 & 0,46 \\
\hline 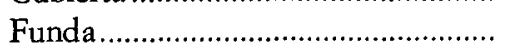 & 0,04 & 0,02 & 0,03 & 2,69 & 0,05 & 0,64 & 4,47 & 0,90 & 1,77 \\
\hline 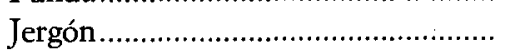 & 3,16 & 1,04 & 1,50 & 2,62 & 1,01 & 1,37 & 2,34 & 1,18 & 1,46 \\
\hline Pajero & - & 0,17 & 0,14 & - & 0,35 & 0,27 & 0,16 & 0,37 & 0,32 \\
\hline Sábana .......... & 5,84 & 2,55 & 3,26 & 10,10 & 2,60 & 4,28 & 10,75 & 3,64 & 5,36 \\
\hline Total ropa de cama.. & $\begin{array}{l}31,92 \\
(798)\end{array}$ & $\begin{array}{c}14,62 \\
(1.345)\end{array}$ & $\begin{array}{c}18,32 \\
(2.143)\end{array}$ & $\begin{array}{r}39,59 \\
(1.148)\end{array}$ & $\begin{array}{c}13,56 \\
(1.370)\end{array}$ & $\begin{array}{c}19,37 \\
(2.518) \\
\end{array}$ & $\begin{array}{r}42,06 \\
(1.346) \\
\end{array}$ & $\begin{array}{c}18,50 \\
(1.850) \\
\end{array}$ & $\begin{array}{c}24,21 \\
(3.196) \\
\end{array}$ \\
\hline
\end{tabular}


CUADRO 1 (Cont.)

Numero de piezas textiles por familia: Palencia, 1750-1840

\begin{tabular}{|c|c|c|c|c|c|c|c|c|c|}
\hline \multirow{2}{*}{ Artículos textiles } & \multicolumn{3}{|c|}{$1752-1765$} & \multicolumn{3}{|c|}{$1785-1800$} & \multicolumn{3}{|c|}{$1830-1840$} \\
\hline & Ciudad & Campo & TOTAL & Citudad & Campo & TOTAL & Ciudad & Campo & TOTAL \\
\hline 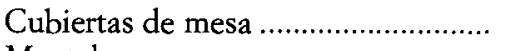 & 0,72 & 0,47 & 0,52 & 1,41 & 0,42 & 0,64 & 1,13 & 0,77 & 0,86 \\
\hline 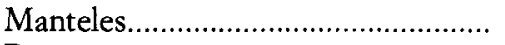 & 2,62 & 1,39 & 1,65 & 2,14 & 1,26 & 1,45 & 2,13 & 1,59 & 1,72 \\
\hline 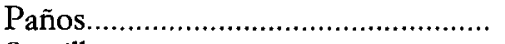 & 0,32 & 0,67 & 0,60 & 0,28 & 0,31 & 0,30 & 0,19 & 0,22 & 0,21 \\
\hline 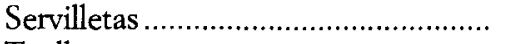 & 5,04 & 2,30 & 2,89 & 9,28 & 2,14 & 3,73 & 4,92 & 2,59 & 3,16 \\
\hline Toallas.. & 2,64 & 0,36 & 0,85 & 3,14 & 0,31 & 0,94 & 2,47 & 0,73 & 1,15 \\
\hline Total ropa blanca del hogar................. & $\begin{array}{l}11,34 \\
(283)\end{array}$ & $\begin{array}{r}5,19 \\
(477)\end{array}$ & $\begin{array}{r}6,50 \\
(761)\end{array}$ & $\begin{array}{l}16,24 \\
(471)\end{array}$ & $\begin{array}{r}4,43 \\
(447)\end{array}$ & $\begin{array}{r}7,07 \\
(918)\end{array}$ & $\begin{array}{l}10,83 \\
(346)\end{array}$ & $\begin{array}{r}5,90 \\
(589)\end{array}$ & $\begin{array}{r}7,09 \\
(936)\end{array}$ \\
\hline Cortinas.. & 5,00 & 0,26 & 1,27 & 7,48 & 0,50 & 2,05 & 6,06 & 1,02 & 2,24 \\
\hline 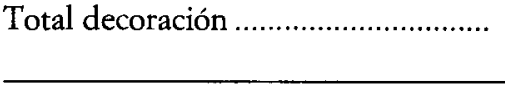 & $\begin{array}{r}5,00 \\
(125) \\
\end{array}$ & $\begin{array}{l}0,26 \\
(24) \\
\end{array}$ & $\begin{array}{r}1,27 \\
(149) \\
\end{array}$ & $\begin{array}{r}7,48 \\
(217) \\
\end{array}$ & $\begin{array}{c}0,50 \\
(50) \\
\end{array}$ & $\begin{array}{r}2,05 \\
(267) \\
\end{array}$ & $\begin{array}{c}6,06 \\
(194) \\
\end{array}$ & $\begin{array}{r}1,02 \\
(102) \\
\end{array}$ & $\begin{array}{r}2,24 \\
(296) \\
\end{array}$ \\
\hline 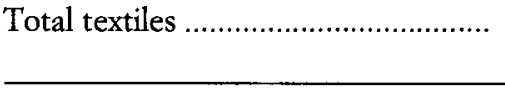 & $\begin{array}{c}90,66 \\
(2.266) \\
\end{array}$ & $\begin{array}{c}37,03 \\
(3.406) \\
\end{array}$ & $\begin{array}{r}48,49 \\
(5.673) \\
\end{array}$ & $\begin{array}{r}117,38 \\
(3.404) \\
\end{array}$ & $\begin{array}{c}40,20 \\
(4.060) \\
\end{array}$ & $\begin{array}{c}57,42 \\
(7.464) \\
\end{array}$ & $\begin{array}{r}129,73 \\
(4.151) \\
\end{array}$ & $\begin{array}{c}47,66 \\
(4.765) \\
\end{array}$ & $\begin{array}{c}67,55 \\
(8.917) \\
\end{array}$ \\
\hline Inventarios disponibles ......................... & 25,00 & 92,00 & 117,00 & 29,00 & 101,00 & 130,00 & 32,0 & 100,00 & 132,00 \\
\hline \multicolumn{10}{|c|}{$\begin{array}{l}\text { NOTA: Entre paréntesis figura el número total de piezas textiles. } \\
\text { FuENTE: Archivo Histórico Provincial de Palencia. Véase Bibliografía. }\end{array}$} \\
\hline
\end{tabular}


el incremento de los juegos de sábanas —en estrecha relación con la formación de las dotes femeninas-, el aumento de los colchones - más acentuado en la ciudad que en los ámbitos rurales, al mismo tiempo que disminuyen los jergones- y de las colchas. Por lo que se refiere a las almohadas, cobertores y mantas y cubiertas de cama se mantienen en cifras muy similares entre 1750 y 1840 . Disminuyen, sin embargo, los cabezales y persiste la poca presencia de pajeros, reducidos casi única y exclusivamente a los núcleos rurales. Finalmente, en cuanto a los otros grupos textiles -ropa blanca del hogar y cortinas- presentan un crecimiento moderado poco perceptible.

Un aspecto que llama poderosamente la atención es que este crecimiento en el consumo textil fue mucho más acusado en la ciudad que en los ámbitos rurales, lo cual vendría a resaltar el papel desarrollado por las ciudades en la difusión de nuevas pautas de consumo textil. Baste tan sólo citar como ejemplo a la indumentaria personal. En la ciudad de Palencia las prendas de vestir por inventario alcanzan las cifras de 42,54 y 70 en cada uno de los tres cortes temporales mencionados, mientras que en los inventarios procedentes del campo palentino la media baja sensiblemente hasta las 16, 21 y 22 prendas por familia. Este hecho corrobora las opiniones vertidas por la historiografía económica internacional. Así, por ejemplo, McKendrick ha enfatizado la importancia de Londres como un centro de consumo básico desde donde las modas se habrían difundido con mayor rapidez, no sólo por los efectos de emulación e imitación debidos a la mayor concentración de población, sino por la implantación y desarrollo de nuevas técnicas comerciales que tienen que ver con la promoción de los productos y el establecimiento de tiendas estables ${ }^{3}$. Igualmente Shammas ${ }^{4} \mathrm{y}$ Weatherill ${ }^{5}$ han puesto de relieve las relaciones entre núcleos urbanos y pautas de consumo, e incluso Borsay ${ }^{6}$ con núcleos de menor densidad demográfica ha llegado a conclusiones similares. En definitiva, se tiende a ver las ciudades como centros desde los cuales surgen hábitos de consumo que se «exportan» a los ámbitos rurales ${ }^{7}$.

Otra cuestión que ha requerido mi atención han sido los cambios acaecidos en las pautas de consumo textil. En primer lugar, he comprobado cuál era la importancia del gasto familiar en textiles en relación con el

\footnotetext{
${ }^{3}$ McKendrick (1982), p. 58.

${ }^{4}$ Shammas (1990).

5 Weatherill (1988).

${ }^{6}$ Borsay (1989), pp. 315-319.

${ }^{7}$ Hohenberg (1993), pp. 263-282.
} 


\section{CUADRO 2}

Estructura del stock familiar en bienes duraderos y semiduraderos, Palencia 1750-1850

En porcentaje sobre el valor del stock inventariado de bienes de consumo doméstico

Indice de precios Moreno. Base $100=1780-1784$

\begin{tabular}{|c|c|c|c|}
\hline Capitulos de gasto & $1752-1765$ & $1785-1800$ & $1830-1840$ \\
\hline 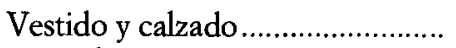 & 32,92 & 34,08 & 28,13 \\
\hline 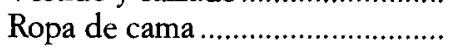 & 21,54 & 23,30 & 22,58 \\
\hline Ropa blanca del hogar ...................... & 2,63 & 2,34 & 2,11 \\
\hline Textiles de decoración.................... & 0,45 & 0,69 & 0,66 \\
\hline 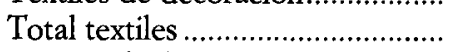 & 57,55 & 60,41 & 53,47 \\
\hline Menaje del hogar ${ }^{*} \ldots \ldots \ldots \ldots \ldots \ldots \ldots$ & 38,93 & 36,25 & 43,38 \\
\hline Stock en cultura: libros .................. & 0,19 & 0,60 & 0,63 \\
\hline 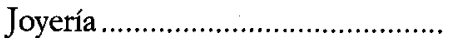 & 3,11 & 2,48 & 2,19 \\
\hline 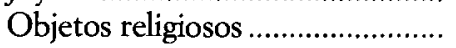 & 0,19 & 0,22 & 0,22 \\
\hline 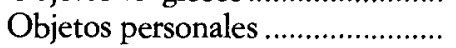 & 0,03 & 0,02 & 0,10 \\
\hline $\begin{array}{l}\text { Stock de consumo medio en rea- } \\
\text { les constantes............................... }\end{array}$ & $1.584,54$ & $1.656,36$ & $1.633,95$ \\
\hline 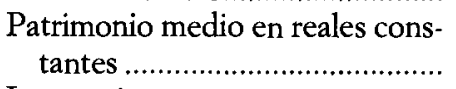 & $19.789,17$ & $21.208,80$ & $21.745,90$ \\
\hline 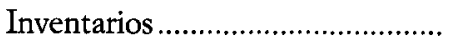 & 114,00 & 129,00 & 132,00 \\
\hline
\end{tabular}

* Incluye mobiliario, accesorios de casa, útiles de cocina, loza, objetos de decoración y pinturas.

FuEnte: Archivo Histórico Provincial de Palencia. Véase Bibliografía.

resto de los bienes duraderos y semiduraderos. En este sentido, en el cuadro 2 se observa que entre 1750 y 1850 no existen modificaciones sustanciales en la estructura del gasto familiar en bienes duraderos y semiduraderos -medido a través del valor del stock inventariado de bienes de consumo doméstico- de los hogares castellanos. Asimismo se aprecia que el componente más importante de dicho stock está constituido por la suma total de los textiles, la cual se sitúa en un porcentaje uniforme cercano al 60 por 100 entre 1750 y 1800 , apreciándose una trayectoria descendente en 1830-1840. Dentro de los mismos, mientras la ropa de cama, la ropa blanca del hogar y los textiles utilizados en decoración han ido manteniendo o disminuyendo ligeramente su peso en el gasto global (en torno al 22 por 100 , al 2,5 por 100 y al 0,6 por 100 respectivamente), 
el gasto dedicado al vestido y al calzado, cada vez más dependiente de los vaivenes de la moda, ha descendido en torno a seis puntos en 1830-1840, tras haberse mantenido relativamente constante el porcentaje medio, alrededor del 33-34 por 100, entre 1750 y 1800 .

En otro orden de cosas, en el gráfico 1 se observa que las familias castellanas empleaban más de la mitad del presupuesto asignado a la compra de textiles a la adquisición de indumentaria personal. Dicho presupuesto no experimentó cambios significativos entre 1750 y 1840 , apreciándose únicamente una ligera disminución en el peso del vestido y el calzado en detrimento de la ropa de cama. De hecho, mientras el gasto en vestido y calzado pasó del 57 al 53 por 100 entre 1750 y 1840 , el gasto en ropa de cama se incrementó en cinco puntos porcentuales pasando del 37 al 42 por 100 por las mismas fechas. Por lo que se refiere al gasto en ropa de mesa y de aseo - oscilaciones entre el 4 y el 5 por 100 y en decoración - en torno al 1 por 100 - no presentó variaciones sustanciales. Tampoco se observan grandes diferencias en la estructura del gasto textil según el inventario post mortem provenga de la ciudad o de los núcleos rurales. No obstante, se puede apuntar que el gasto en ropa de cama y en ropa blanca del hogar - ropa de mesa y de aseo- fue mayor en el caso de los núcleos rurales. Por el contrario, el gasto en indumentaria personal -a excepción del período comprendido entre 1785 y 1800 - y en decoración interior fue relativamente superior en la ciudad.

En cuanto a la fibra textil utilizada en la confección de los tejidos, el primer aspecto que sobresale es la progresiva importancia del algodón. De una presencia casi testimonial del 4 por 100 a mediados del siglo xvII se pasa al 29 por 100 en $1830-1840$, porcentaje casi idéntico al representado por la lana (34 por 100) y los lienzos de lino (28 por 100). Este incremento en el uso del algodón se hace fundamentalmente a costa de la lana que reduce paulatinamente su importancia ${ }^{8}$. Parece, asimismo, que la irrupción del algodón fue mucho más lenta y tardía en los núcleos rurales con menor capacidad de apertura hacia el mercado. Baste significar que en 1785-1800 el algodón representaba el 17 por 100 en las zonas urbanas mientras que en el campo apenas llegaba al 4 por 100 . De ahí que no sorprenda que

\footnotetext{
${ }^{8}$ Es notoria la progresiva pérdida de importancia de la lana. Así, por ejemplo, en 1752-1765 la lana representaba el 55 por 100 del total de los tejidos utilizados en la confección de las prendas, disminuyendo seis puntos (49 por 100) en 1785-1800, para acabar en torno al 34 por 100 a mediados del siglo xx. Por lo que se refiere a los lienzos de lino, éstos presentan un ligero descenso que va desde el 35 por 100 a mediados del setecientos al 31 por 100 en $1785-1800$ para situarse alrededor del 28 por 100 en $1830-1840$. En cuanto a la seda, ésta se mantuvo constante desde 1785-1800 en torno al 9 por 100 .
} 


\section{GRÁFICO 1}

Estructura del stock de textiles en porcentajes: Palencia 1750-1850

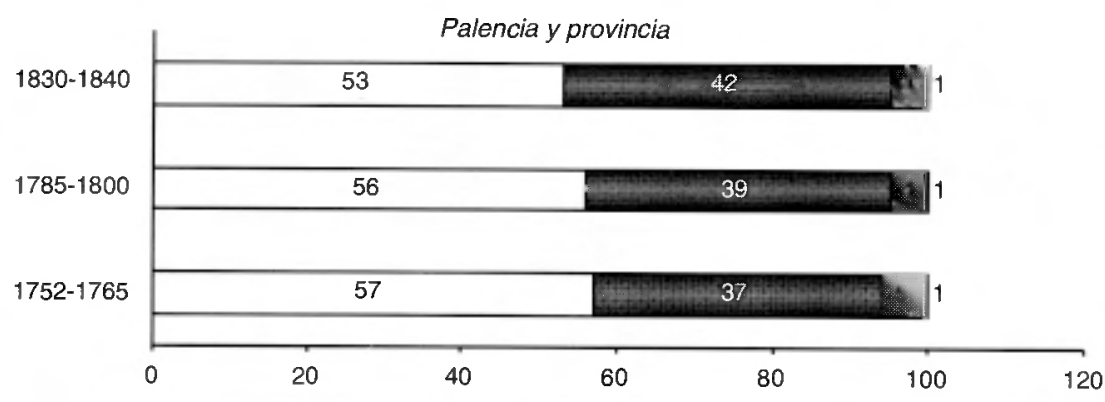

$\square$ Vestido y calzado $\square$ Ropa de cama $\square$ Ropa blanca del hogar $\square$ Decoración

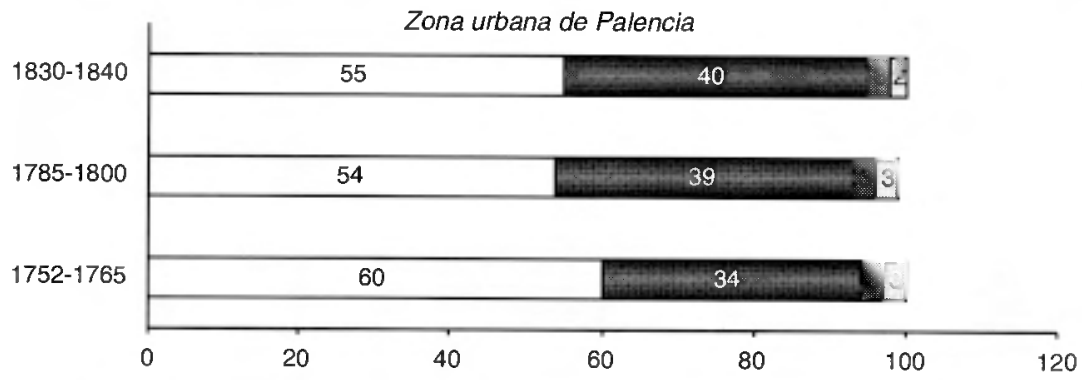

$\square$ Vestido y calzado $\square$ Ropa de cama $\square$ Ropa blanca del hogar $\square$ Decoración

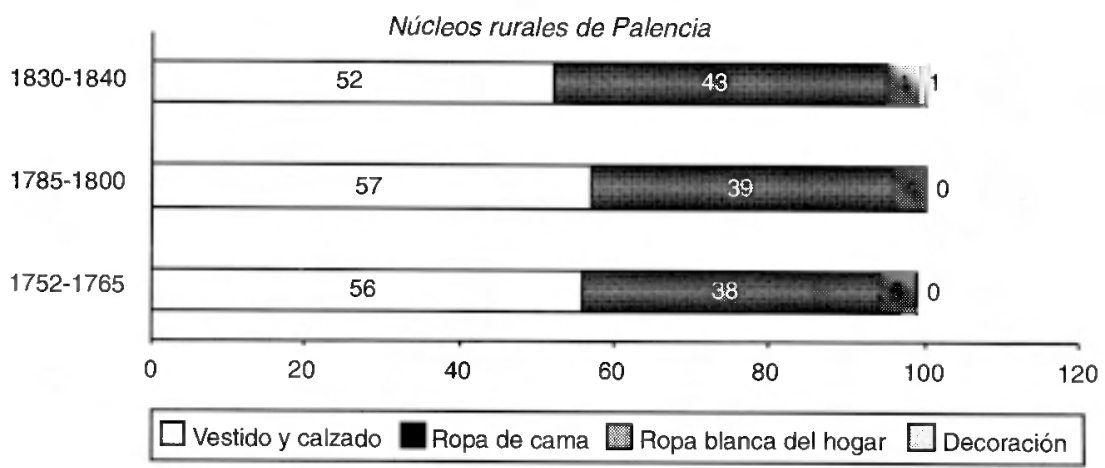

Fuente: Archivo Histórico Provincial de Palencia. Véase Bibliografía. 


\section{GRÁFICO 2}

Pautas de consumo textil en función de la fibra utilizada en la confección del tejido

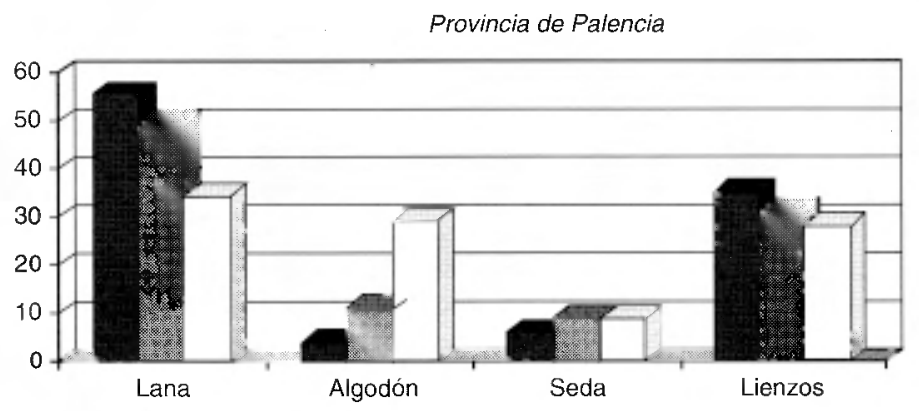

1752-1765

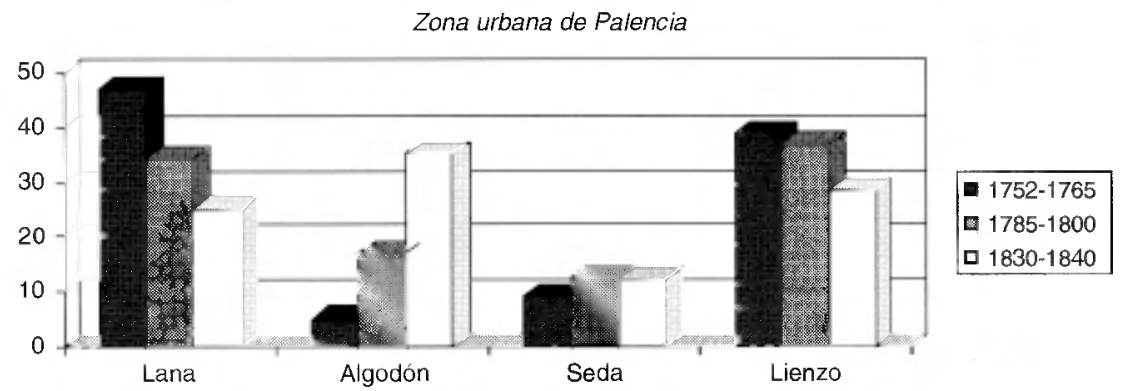

Núcleos rurales de Palencia

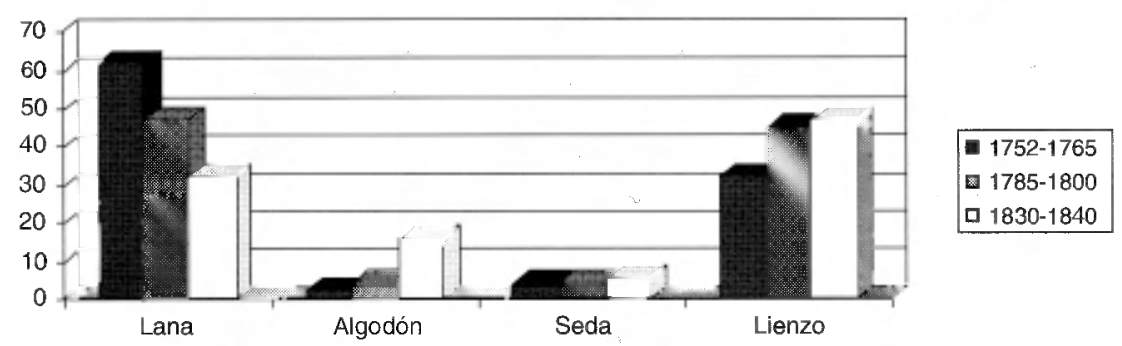

FuENTE: Archivo Histórico Provincial de Palencia. Véase Bíbliografía. 
los cambios enunciados anteriormente fueran más acusados en la ciudad o en los núcleos más dinámicos. En concreto, en 1830-1840 mientras el algodón se convertía dentro de la capital palentina en la fibra más utilizada con unas cifras en torno al 35 por 100, por encima de los lienzos de lino (28 por 100$)$ y de la lana (25 por 100$)$, por el contrario, en los núcleos rurales su importancia apenas alcanzaba el 15 por 100, muy lejos de las otras fibras textiles más tradicionales. Por lo que se refiere a los núcleos rurales, la supremacía de la lana únicamente fue discutida por los lienzos de lino ${ }^{9}$, lo cual estaría íntimamente ligado con el desarrollo de las industrias textiles rurales de la provincia y la entrada de lienzo gallego ${ }^{10}$ que ofrecían sus productos textiles a un precio mucho más asequible para las economías familiares que la industria urbana y sus tejidos de lana. En suma, para el consumidor castellano que reside en zonas urbanas con un mayor grado de apertura al mercado los productos laneros son menos atractivos debido al desarrollo de la industria algodonera, mientras que en el campo los lienzos de lino (industria rural dispersa) van a precipitar la paulatina pérdida de importancia de los tejidos de lana entre las economías campesinas. Por último, un análisis más exhaustivo (véase el cuadro 3) indica que este aumento de piezas textiles que utilizaban algodón venía motivada por su mayor empleo en la indumentaria personal (en detrimento de la lana) y en la ropa de cama y de hogar (sustituyendo a los lienzos de lino), así como por la generalización de su uso en la confección de cortinas.

Estas pautas de consumo de textil se manifestaron con mayor rapidez en la ciudad a partir del período 1785-1800, mientras que en los entornos rurales hubo que esperar hasta bien entrado el siglo XIX. Si bien los tejidos de lana habían visto perder parte de su importancia relativa, todavía seguían siendo los más utilizados en 1830-1840 para confeccionar la indumentaria personal de las familias castellanas, representando aproximadamente el 50 por 100 de las prendas, casi el doble que las prendas de algodón ( 24 por 100) y muy por delante de las de seda (16 por 100) o de las de lienzos de lino (9 por 100). En la ropa de cama y en la ropa blanca del hogar la fibra más utilizada a mediados del siglo XIX continuaba siendo

${ }^{9}$ En 1752-1765 la lana representaba el 62 por 100, treinta puntos más que los lienzos. En 1785-1800 el porcentaje representado por la lana y los lienzos de lino prácticamente se ha equiparado con cifras en torno al 47 por 100 y al 45 por 100 respectivamente. En 1830-1840 la lana ha cedido el primer puesto a los lienzos de lino, los cuales se sitúan sobre el 47 por 100 mientras que los tejidos de lana han caído hasta el 32 por 100. Más lejos todavía se encuentran los tejidos de algodón (16 por 100) y de seda (4 por 100).

${ }^{10}$ Carmona (1990). 
CUADRO 3

Porcentaje que representa cada fibra textil: Palencia 1750-1840

\begin{tabular}{|c|c|c|c|c|c|c|c|c|c|c|}
\hline \multirow{2}{*}{ Grupo textil } & \multirow[b]{2}{*}{ Fibra textil } & \multicolumn{3}{|c|}{$1752-1765$} & \multicolumn{3}{|c|}{$1785-1800$} & \multicolumn{3}{|c|}{$1830-1840$} \\
\hline & & Ciudad & Campo & TOTAL & Ciudad & Campo & TOTAL & Ciudad & Campo & TOTAL \\
\hline \multirow{5}{*}{ Vestido-calzado } & Lana & 67,04 & 79,91 & 74,63 & 51,54 & 77,77 & 65,89 & 42,11 & 61,72 & 50,65 \\
\hline & Algodón & 2,15 & 2,61 & 2,42 & 17,06 & 5,34 & 10,50 & 26,66 & 20,34 & 23,91 \\
\hline & Seda & 14,63 & 6,73 & 10,01 & 15,81 & 7,38 & 11,10 & 20,78 & 10,59 & 16,35 \\
\hline & Lienzos & 16,03 & 10,75 & 12,94 & 15,58 & 10,11 & 12,51 & 10,44 & 7,35 & 9,10 \\
\hline & Piezas & 648,00 & 921,00 & $1.569,00$ & 809,00 & $1.029,00$ & $1.838,00$ & 919,00 & 708,00 & $1.627,00$ \\
\hline \multirow{5}{*}{ Ropa de cama } & Lana & 12,13 & 32,22 & 23,91 & 7,00 & 31,44 & 17,65 & 6,24 & 27,59 & 15,85 \\
\hline & Algodón & 9,50 & 1,86 & 5,02 & 16,42 & 5,67 & 11,43 & 35,36 & 22,12 & 29,40 \\
\hline & Seda & 1,06 & 0,19 & 0,55 & 2,84 & - & 1,60 & 0,96 & 0,98 & 0,97 \\
\hline & Lienzos & 77,31 & 65,73 & 70,52 & 73,75 & 62,90 & 69,01 & 57,44 & 49,31 & 53,79 \\
\hline & Piezas & 379,00 & 537,00 & 916,00 & 457,00 & 353,00 & 810,00 & 625,00 & 511,00 & $1.136,00$ \\
\hline \multirow[t]{5}{*}{ Ropa de hogar } & Lana & 14,28 & 21,21 & 17,65 & 6,50 & 29,41 & 10,64 & 17,78 & 6,34 & 11,11 \\
\hline & Algodón & 5,71 & 3,03 & 4,41 & 2,60 & - & 2,13 & 44,44 & 25,39 & 33,33 \\
\hline & Seda & 14,28 & - & 7,3 & 19,48 & - & 15,96 & - & 4,76 & 2,78 \\
\hline & Lienzos & 65,72 & 75,76 & 70,59 & 71,42 & 70,59 & 71,28 & 37,77 & 63,50 & 52,78 \\
\hline & Piezas & 35,00 & 33,00 & 68,00 & 77,00 & 17,00 & 94,00 & 45,00 & 63,00 & 108,00 \\
\hline \multirow[t]{5}{*}{ Decoración } & Lana & 58,51 & 60,04 & 58,65 & 35,09 & 61,88 & 38,02 & 0,73 & 7,98 & 1,86 \\
\hline & Algodón & 2,12 & 9,99 & 2,88 & 25,74 & 9,51 & 23,96 & 84,56 & 64,00 & 81,37 \\
\hline & Seda & - & - & - & 15,20 & - & 13,54 & 5,15 & - & 4,35 \\
\hline & Lienzos & 39,37 & 29,96 & 38,46 & 23,97 & 28,61 & 24,48 & 9,55 & 28,02 & 12,42 \\
\hline & Piezas & 94,00 & 10,00 & 104,00 & 171,00 & 21,00 & 192,00 & 136,00 & 25,00 & 161,00 \\
\hline
\end{tabular}

FuenTE: Archivo Histórico Provincial de Palencia. Véase Bibliografía. 
el lienzo de lino con algo más del 50 por 100, lejos, sin embargo, del 70 por 100 que representaban en 1752-1765. En cuanto a los textiles usados en la decoración interior de la casa (cortinas), la fibra más utilizada fue el algodón que pasó de un insignificante 3 por 100 a mediados del siglo XVIII a un 80 por 100 en la década de $1830-1840$.

\section{UNA LLAMADA A LA PRECAUCIÓN DEBIDO AL RELATIVO DESCONOCIMIENTO DE LOS RITMOS DE REPOSICIÓN TEXTIL}

Siempre puede existir la duda sobre sí este crecimiento en el stock de textiles pudo ser debido a un aumento en el consumo de prendas usadas y viejas procedentes de mercados de segunda mano muy abundantes, por otra parte, en la mayoría de las ciudades europeas del siglo $\mathrm{XIX}^{11}$. Para solucionar este problema debería calcular el flujo de gasto anual en textiles, lo cual rebasa con creces el objeto de este artículo ${ }^{12}$. En principio, habría que averiguar la vida útil de los bienes textiles ${ }^{13}$ y estimar sus ritmos de

${ }^{11}$ Según afirma Teófilo Gautier, «un día paseábamos por una de las calles vecinas a la plaza (Burgos), notamos en la entrada de un antiguo pórtico un vaivén de gentes, hombres y mujeres, la mayoría de los cuales estaban cubiertos con esos famosos harapos [...] Habiendo reparado en una joven vendedora de carbón, que vivía enfrente, le preguntamos qué era aquello. Nos respondió, enrojeciendo, que era el mercado de la liendre, nombre que se da a los huevos de cierto insecto parásito que se adhiere demasiado a la caballera humana (piojo) ... Este pintoresco mercado, aunque demasiado hormigueante, nos recordó el de Houndsditch, que habíamos visitado en Londres con Doré, y el de los andrajos de Estrasburgo». Véase a tales efectos los viajes de Jean Charles Davillier hacia 1862 por la provincia de Burgos en García Simón (1999), pp. 100-101.

${ }_{12}$ Con respecto a cómo transformar variables stock en flujos, véase Ramos (2001b), capítulo 3.

${ }_{13}$ Para calcular la vida media estimada de los bienes disponemos de las curadurías recogidas en los distintos protocolos notariales, de las estimaciones realizadas por Cerdá en su «Monografía Estadística de la clase obrera de Barcelona en 1856», y de las monografías de Le Play a mediados del siglo XIX sobre los obreros europeos (en el caso español una familia de pescadores donostiarra y una familia de campesinos cántabros). Aunque se puede discutir sobre si la duración estimada en años para cada uno de los artículos fue la correcta, de todos ellos los datos más completos corresponden a Cerdá. En este sentido, la duración de un par de zapatos, calzoncillos, blusas para el trabajo, pantalones, chalecos y gorras no excede, sorprendentemente, más de un año o como mucho dos para el caso de las chaquetas y las blusas. Por contra, la duración del ajuar doméstico es muy superior: desde los seis años que duran las fundas para las almohadas hasta los diez o veinte años que duran, respectivamente, las sábanas y las colchas, pasando por los ocho años en que se estima el ritmo de reposición para las almohadas y los jergones. Por su parte, los manteles 
reposición o tasas de depreciación. Esto último es relativamente menos laborioso y sería un buen indicador sobre la cuestión primordial a debatir en este punto, es decir, comprobar si el aumento de las piezas textiles se debió o no a un mayor uso de las piezas de segunda mano. Para ello debo recabar la información proporcionada por los inventarios post mortem sobre los niveles de reposición de los artículos textiles. Como es bien sabido, la información proporcionada por los inventarios post mortem alude en determinadas ocasiones al estado de conservación de los productos. En este aspecto, varias son las acepciones utilizadas por el escribano - nuevo, bueno, usado, andado, remendado, viejo y roto, por citar las más comunes- a la hora de calificar el estado de conservación de los productos duraderos y semiduraderos. Obviamente, los conceptos reseñados difieren no sólo entre uno u otro escribano, sino que es muy probable que las percepciones varíen a lo largo del tiempo; sin embargo, a pesar de las apreciaciones subjetivas y de las connotaciones que ello conlleva, sí es evidente que un aumento, por ejemplo, de los productos nuevos, sí significaría un crecimiento en el consumo de bienes textiles. Por tales razones, he considerado tres categorías que engloban a todos los registros especificados anteriormente: bueno o nuevo, usado y viejo. En el cuadro 4 se observa que el porcentaje de artículos textiles en los cuales se especifica su estado de conservación gira alrededor del 25 por 100 , siendo normalmente este porcentaje mayor en la indumentaria personal y en la ropa de cama y más pequeño en la ropa del hogar y en los artículos textiles de decoración.

A partir de la información recogida en el cuadro 5 se puede apreciar el ritmo de reposición de los artículos textiles entre 1750 y 1840 . Considerando la poca cantidad de piezas textiles relativas a la ropa de hogar (ropa de mesa y ropa de aseo) y a la decoración interior (cortinas) en las cuales se indique el estado de conservación de las mismas; se puede afirmar, en términos globales, que las piezas nuevas se situaban en torno al 30 por 100 , las usadas sobrepasaban el 35 por 100 , mientras que los artículos viejos no llegaban a este último porcentaje. Asimismo, se observa que la totalidad de piezas viejas disminuyeron conforme avanzábamos en el tiempo. Mientras que, por el contrario, los artículos textiles usados aumentaron en 1830-1840 y los nuevos se mantuvieron o bajaron ligeramente ${ }^{14}$.

y las toallas o paños de mano duraban entre cuatro y nueve años. Véase Cerdá (1867), pp. 651-655, y Le Play (1990).

${ }^{14} \mathrm{La}$ trayectoria de las piezas nuevas en la ciudad presenta siempre en todas las categorías textiles (vestido-calzado, ropa de cama, ropa de hogar y decoración) forma de 


\section{CUADRO 4}

Información proporcionada por los inventarios post mortem sobre el estado de conservación de los bienes textiles, Palencia 1750-1840

En porcentajes sobre el total de piezas de cada grupo

\begin{tabular}{|c|c|c|c|c|c|c|c|c|c|}
\hline & \multicolumn{3}{|c|}{$1752-1765$} & \multicolumn{3}{|c|}{$1785-1800$} & \multicolumn{3}{|c|}{$1830-1840$} \\
\hline & Ciudad & Campo & TOTAL & Ciudad & Campo & TOTAL & Ciudad & Campo & TOTAL \\
\hline 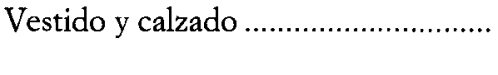 & $\begin{array}{c}25,33 \\
(1.066)\end{array}$ & $\begin{array}{c}34,31 \\
(1.571)\end{array}$ & $\begin{array}{c}30,68 \\
(2.637)\end{array}$ & $\begin{array}{c}29,42 \\
(1.567)\end{array}$ & $\begin{array}{c}22,69 \\
(2.204)\end{array}$ & $\begin{array}{c}25,48 \\
(3.771)\end{array}$ & $\begin{array}{c}26,51 \\
(2.267)\end{array}$ & $\begin{array}{c}24,90 \\
(2.233)\end{array}$ & $\begin{array}{c}25,71 \\
(4.500)\end{array}$ \\
\hline Ropa de cama & $\begin{array}{l}41,87 \\
(824)\end{array}$ & $\begin{array}{c}38,02 \\
(1.415)\end{array}$ & $\begin{array}{c}39,44 \\
(2.239)\end{array}$ & $\begin{array}{c}30,58 \\
(1.164)\end{array}$ & $\begin{array}{c}24,33 \\
(1.492)\end{array}$ & $\begin{array}{c}27,07 \\
(2.656)\end{array}$ & $\begin{array}{c}39,20 \\
(1.370)\end{array}$ & $\begin{array}{c}24,88 \\
(2.046)\end{array}$ & $\begin{array}{c}30,62 \\
(3.416)\end{array}$ \\
\hline Ropa de hogar. & $\begin{array}{l}16,18 \\
(291)\end{array}$ & $\begin{array}{l}20,10 \\
(482)\end{array}$ & $\begin{array}{l}18,63 \\
(773)\end{array}$ & $\begin{array}{l}18,66 \\
(477)\end{array}$ & $\begin{array}{l}12,23 \\
(462)\end{array}$ & $\begin{array}{l}15,50 \\
(939)\end{array}$ & $\begin{array}{l}42,72 \\
(354)\end{array}$ & $\begin{array}{l}11,91 \\
(604)\end{array}$ & $\begin{array}{l}22,96 \\
(958)\end{array}$ \\
\hline Decoración.... & $\begin{array}{l}35,20 \\
(125)\end{array}$ & $\begin{array}{l}4,17 \\
(24)\end{array}$ & $\begin{array}{l}30,20 \\
(149)\end{array}$ & $\begin{array}{l}23,04 \\
(217)\end{array}$ & $\begin{array}{l}6,00 \\
(50)\end{array}$ & $\begin{array}{l}19,85 \\
(267)\end{array}$ & $\begin{array}{l}12,89 \\
(194)\end{array}$ & $\begin{array}{r}5,88 \\
(102)\end{array}$ & $\begin{array}{l}10,47 \\
(296)\end{array}$ \\
\hline Total bienes textiles. & $\begin{array}{c}30,62 \\
(2.306)\end{array}$ & $\begin{array}{c}33,64 \\
(3.492)\end{array}$ & $\begin{array}{c}32,44 \\
(5.798)\end{array}$ & $\begin{array}{c}27,91 \\
(3.425)\end{array}$ & $\begin{array}{c}21,92 \\
(4.208)\end{array}$ & $\begin{array}{c}24,61 \\
(7.633)\end{array}$ & $\begin{array}{c}31,40 \\
(4.185)\end{array}$ & $\begin{array}{c}22,93 \\
(4.985)\end{array}$ & $\begin{array}{c}26,76 \\
(9.170)\end{array}$ \\
\hline
\end{tabular}

NotA: Entre paréntesis figura el número total de piezas textiles.

FuENTE: Archivo Histórico Provincial de Palencia. Véase Bibliografía. 
CUADRO 5

Información relativa al estado de conservación de los distintos grupos textiles, Palencia 1750-1840 En porcentajes sobre el total de las piezas textiles

\begin{tabular}{|c|c|c|c|c|c|c|c|c|c|}
\hline & \multicolumn{3}{|c|}{$1752-1765$} & \multicolumn{3}{|c|}{$1785-1800$} & \multicolumn{3}{|c|}{$1830-1840$} \\
\hline & Ciudad & Campo & TOTAL & Ciudad & Campo & TOTAL & Ciudad & Campo & TOTAL \\
\hline \multicolumn{10}{|l|}{ Total textiles: } \\
\hline 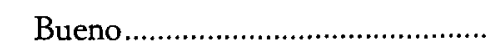 & 23,51 & 30,55 & 27,91 & 38,91 & 25,91 & 32,53 & 27,92 & 29,31 & 28,57 \\
\hline Usado & 32,72 & 31,66 & 32,06 & 35,04 & 27,05 & 31,12 & 42,26 & 31,32 & 37,16 \\
\hline Viejo & 43,77 & 37,79 & 40,03 & 26,05 & 47,05 & 36,36 & 29,82 & 39,37 & 34,27 \\
\hline 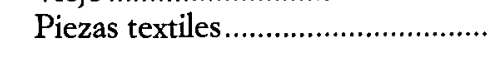 & 706,00 & $1.175,00$ & $1.881,00$ & 956,00 & 922,00 & $1.878,00$ & $1.311,00$ & $1.143,00$ & $2.454,00$ \\
\hline \multicolumn{10}{|l|}{ Vestido y calzado: } \\
\hline 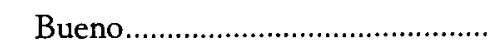 & 27,04 & 31,91 & 30,28 & 30,59 & 27,80 & 29,14 & 21,46 & 29,14 & 25,15 \\
\hline Usado & 38,89 & 25,97 & 30,28 & 37,74 & 29,20 & 33,30 & 45,26 & 31,47 & 38,63 \\
\hline 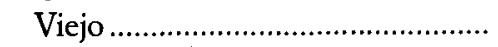 & 34,07 & 42,12 & 39,43 & 31,67 & 43,00 & 37,57 & 33,28 & 39,39 & 36,21 \\
\hline 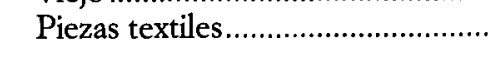 & 270,00 & 539,00 & 809,00 & 461,00 & 500,00 & 961,00 & 601,00 & 556,00 & $1.157,00$ \\
\hline \multicolumn{10}{|l|}{ Ropa de cama: } \\
\hline Bueno & 22,61 & 29,37 & 26,73 & 44,94 & 23,14 & 33,94 & 29,80 & 29,08 & 29,45 \\
\hline 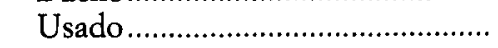 & 29,86 & 34,39 & 32,62 & 34,55 & 24,52 & 29,49 & 40,97 & 31,04 & 36,14 \\
\hline Viejo & 47,54 & 36,25 & 40,66 & 20,51 & 52,34 & 36,58 & 29,24 & 39,88 & 34,42 \\
\hline Piezas textiles...................................... & 345,00 & 538,00 & 883,00 & 356,00 & 363,00 & 719,00 & 537,00 & 509,00 & $1.046,00$ \\
\hline
\end{tabular}




\section{CUADRO 5 (Cont.)}

Información relativa al estado de conservación de los distintos grupos textiles, Palencia 1750-1840 En porcentajes sobre el total de las piezas textiles

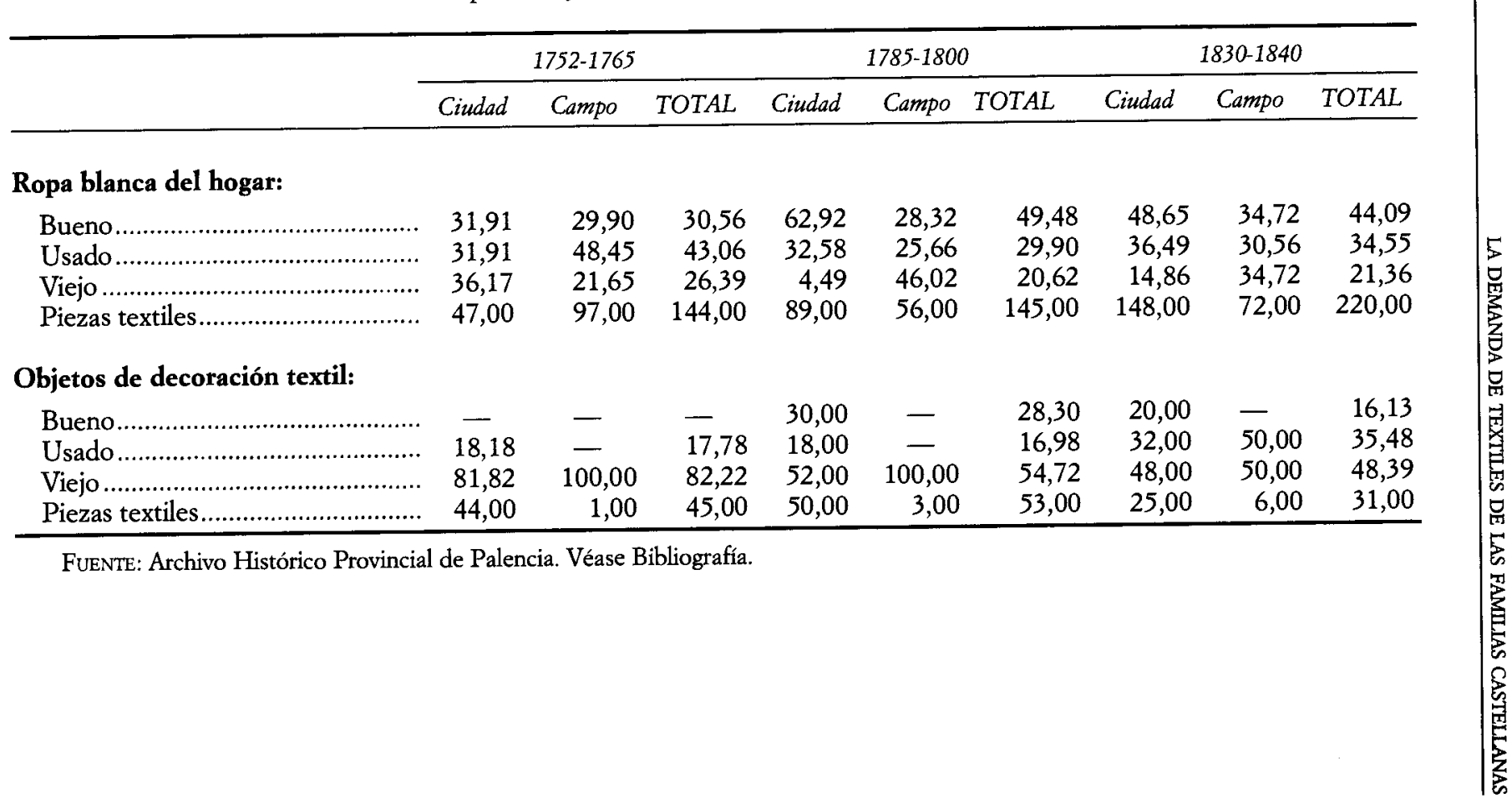


Más detalladamente, en la indumentaria personal se aprecia que las piezas buenas y las viejas se redujeron progresivamente mientras que las usadas aumentaron su peso. En la ropa de cama, es evidente la reducción de las piezas viejas, el aumento de las usadas y la tendencia constante de las piezas buenas. Todo lo cual debe estar en relación con unos ritmos de reposición variables a lo largo del tiempo y probablemente más rápidos, dada la disminución de piezas viejas en detrimento de las usadas. Asimismo, observamos cómo la ropa vieja abundaba más en los entornos rurales que en la ciudad. Las explicaciones de este último hecho pueden ser muy diversas: un poder adquisitivo de la población campesina más pequeño, un menor grado de apertura hacia el mercado, unos mayores costes de transacción y de organización en las redes comerciales, dada la dispersión de la demanda e incluso explicaciones de tipo sociológico y cultural.

La importancia de los estados de conservación - bueno, usado o viejonos pone en la pista sobre el papel desempeñado por la calidad de los textiles en la demanda de los mismos. Para evaluar los efectos de la calidad vamos a utilizar el método de precios hedónicos ${ }^{15}$. Esta metodología se basa en la denominada bipótesis hedónica que considera que los agentes económicos valoran los bienes adquiridos por la utilidad que les reportan sus características y no por los bienes en sí mismos. Es decir, lo que proporciona satisfacción al individuo no es el consumo de un determinado bien duradero o semiduradero, sino las propiedades de dicho bien. Bajo esta hipótesis podemos expresar el precio de los textiles en función de sus características, con lo cual obtendríamos la denominada función de precios hedónicos: $\mathrm{P}(\alpha)=f\left(\alpha_{1}, \ldots, \alpha_{n}\right)$. El textil, $\alpha$, viene representado por un conjunto de características: $\alpha=\left(\alpha_{1}, \ldots, \alpha_{n}\right)$, siendo $\mathrm{P}(\alpha)$ el precio del textil $\alpha$. Dicho de otra forma, esta metodología permite obtener el precio de cada una de las características de un determinado bien (memoria en el caso de un ordenador o fibra en el caso de un textil), estimando el precio total del producto como la suma de lo que vale cada una de sus características.

Según estas premisas, he especificado un modelo econométrico en los cortes temporales señalados con anterioridad (1752-1765, 1785-1800 y

« invertida». Es decir, dado un porcentaje de piezas nuevas en 1752-1765, éste aumenta en 1785-1800 para volver a disminuir en 1830-1840. Al contrario acontece con los núcleos rurales, cuya trayectoria se asemeja a una «v normal», ya que, dado un nivel de piezas nuevas en 1752-1765, este porcentaje disminuye en 1785-1800 para aumentar en 1830-1840.

${ }^{15}$ Véase a tales efectos los trabajos pioneros de Lancaster (1966), pp. 132-157; Griliches (1971), y Rosen (1974), pp. 34-55. 
1830-1840) que trate de averiguar qué factores influían en la calidad de los textiles. La forma funcional adoptada ha sido la semilogarítmica ${ }^{16}$, siendo la variable dependiente el valor (precio) del producto textil recogido en el inventario post mortem por el notario, el cual está reflejando implicitamente la calidad del artículo textil en cuestión. Como variables explicativas he considerado distintas variables ficticias que toman valores $\{1,0\}$ para recoger la presencia o la ausencia de una propiedad. En primer lugar, he utilizado una variable geográfica, que discrimine entre las comarcas de Aguilar, Boedo y Ojeda, Tierra de Campos, Cervera y la capital de Palencia, cuyo objetivo sea capturar las diferencias entre las áreas urbanas y los entornos rurales. Posteriormente, he definido la fibra textil con que se confeccionaba el producto, incluyendo en este apartado el algodón, la lana, los lienzos de lino y la seda ${ }^{17}$. El paso siguiente ha sido incluir el estado de conservación - bueno, viejo o usado- del artículo textil. Asimismo el valor del mismo puede variar en función de que esta prenda sea de color o no lo sea. Finalmente, he definido la marca del producto textil según el inventario post mortem indicase la procedencia (con marca) o no la indicase (sin marca). Dado que una variable cualitativa con varias categorías se determina empleando un número de variables ficticias inferior en una unidad al número de categorías, he tomado como referencia a la ciudad de Palencia, a los lienzos de lino, al estado de conservación

\footnotetext{
${ }^{16}$ Una de las cuestiones primordiales consiste en determinar la forma funcional más adecuada para las estimaciones. Por un lado, Rosen se decantaría según los resultados empíricos obtenidos, es decir, atendiendo a la bondad del ajuste. No obstante Cropper, Deck y McConell (1988), pp. 668-675, señalan que en los casos en donde se sabe con certeza que hay variables explicativas importantes omitidas, las formas funcionales más simples, como la lineal, la semi-logarítmica, doble-logarítmica y Box-Cox lineal, funcionan mejor que las cuadráticas. Este peor funcionamiento se debe al hecho de que en las formas cuadráticas cada precio marginal es dependiente de una mayor cantidad de coeficientes que en otros casos. Otros estudios de similar naturaleza han demostrado asimismo que la utilización de términos de segundo orden introduce problemas adicionales de multicolinealidad, los cuales reducen la significatividad de los términos de primer orden sin suponer una mejora significativa en el ajuste. Véase, en este sentido, Garrod y Willis (1993). En la actualidad, numerosos estudios que tratan de evaluar la calidad en distintos productos siguen el modelo semilogarítmico. Véase, por ejemplo, Liegey (1993), pp. 209-226.

17 En este punto, el lector estará seguramente pensando en la variedad de tejidos textiles existentes, en hilados y urdimbres diferentes, en prendas textiles que están compuestas a partir de dos o más fibras e incluso en la variedad de precios y/o calidades que existen entre los tejidos de una misma fibra, etc. Desafortunadamente, por el momento me ha sido imposible obtener en los inventarios post mortem una muestra lo suficientemente sig. nificativa en términos econométricos para poder contrastar la calidad de los distintos tejidos de lana, algodón, seda y lino. De ahí que me haya decantado por utilizar la fibra textil para reflejar parte de las diferencias en precios y calidades.
} 
bueno, a los colores sin especificar y a los productos sin marca. A pesar de que conforme avanzamos en el tiempo la información adicional sobre las características de los artículos textiles es menos detallada ${ }^{18}$, los resultados reflejados en el cuadro 6 son bastantes concluyentes.

En dicho cuadro se presentan los resultados de la estimación del modelo reproduciéndose el contraste global de significación y el coeficiente de bondad del ajuste que muestra un valor cercano al 50 por 100. La estimación de un modelo semilogarítmico permite una interpretación de los parámetros como efectos implícitos. Esto significa que para una variable ficticia un coeficiente estimado â indica que la presencia de esa característica tiene el efecto de cambiar el precio del producto en un porcentaje igual a $\left(e^{\beta}-1\right)^{*} 100$, es decir, que si la característica está presente, el precio se incrementaría en ese porcentaje ${ }^{19}$. Cuando la variable cualitativa toma

${ }^{18}$ La información adicional proporcionada en los inventarios post mortem sobre los artículos textiles es cada vez menor. En este sentido, mientras entre 1750 y 1765 la fibra textil se indicaba en torno al 60 por 100 de las observaciones disponibles, este porcentaje se redujo hasta el 40 por 100 en la década de 1830 . En cuanto al estado de conservación de las piezas textiles - bueno, usado o viejo- únicamente se menciona el mismo en el 35 por 100 de los casos disponibles para el primer corte cronológico, disminuyendo hasta el 25 por 100 en los dos siguientes cortes temporales. Por lo que se refiere al color de las prendas textiles el porcentaje permanece relativamente constante en torno al 25 por 100. Finalmente, la procedencia de los productos textiles se indica en contadísimas ocasiones oscilando entre el 8 por 100 y el 4 por 100 aproximadamente.

Información disponible en los inventarios post mortem sobre las caracteristicas de los articulos textiles: Palencia, 1750-1840. En porcentaje sobre el total de observaciones disponibles

\begin{tabular}{|c|c|c|c|}
\hline Caracteristicas & $1752-1765$ & $1785-1800$ & $1830-1840$ \\
\hline 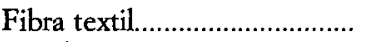 & 59,52 & 50,08 & 40,48 \\
\hline Estado & 34,76 & 25,98 & 25,26 \\
\hline 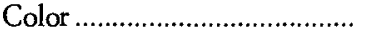 & 27,27 & 24,99 & 25,19 \\
\hline 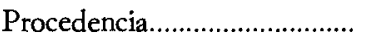 & 7,90 & 5,73 & 3,92 \\
\hline Número de observaciones ..... & 3.444 & 4.157 & 4.696 \\
\hline
\end{tabular}

${ }^{19}$ Recordemos que la hipótesis hedónica supone que el consumidor se interesa por los bienes a causa de las propiedades y características que reúne. Veamos un ejemplo. Si un consumidor tiene que elegir entre un Renault azul y un Mercedes rojo, probablemente escoja el Mercedes por tener mayor potencia y prestaciones. Sin embargo, si tuviera que elegir entre un Renault azul y un Mercedes blanco, elegiría el Renault, ya que no puede soportar la visión del color blanco. En este caso, el valor de la constante (la parte no hedónica) sería el índice de precios nominal o en términos microeconómicos la utilidad del bien en sí mismo. Y dado que la parte no hedónica se ha mantenido constante $(3,166,3,409$ y $3,207)$, esto implicaría que las variaciones en el precio se han producido por cambios en la calidad: variable geográfica, fibra textil, estado de conservación, color y marca. 


\section{CUADRO 6}

Factores determinantes de la calidad de los textiles

Variable dependiente: valor o precio de los artículos textiles en reales

\begin{tabular}{|c|c|c|c|c|c|c|c|c|c|}
\hline \multirow[b]{2}{*}{ Variables explicativas } & \multicolumn{3}{|c|}{$1752-1765$} & \multicolumn{3}{|c|}{$1785-1800$} & \multicolumn{3}{|c|}{$1830-1840$} \\
\hline & Coeficiente & $\begin{array}{c}\text { Efecto } \\
\text { implícito } \\
\%\end{array}$ & $t$-student & Coeficiente & $\begin{array}{c}\text { Efecto } \\
\text { implicito } \\
\%\end{array}$ & $t$-student & Coeficiente & $\begin{array}{c}\text { Efecto } \\
\text { implícito } \\
\%\end{array}$ & t-student \\
\hline 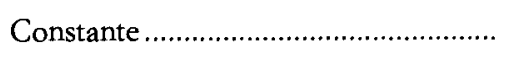 & 3,166 & - & 38,406 & 3,409 & - & 44,162 & 3,217 & - & 31,192 \\
\hline \multicolumn{10}{|l|}{ Variables geográficas: } \\
\hline 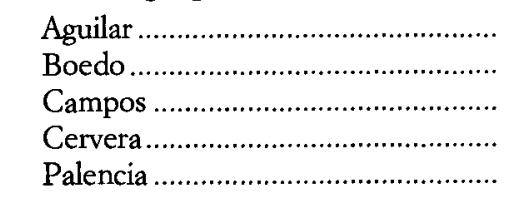 & $\begin{array}{l}-\mathbf{0 , 4 4 2} \\
-\mathbf{0 , 1 8 0} \\
-\mathbf{0 , 3 7 8} \\
-0,222 \\
-\end{array}$ & $\begin{array}{l}-35,73 \\
-16,47 \\
-31,48 \\
-19,91 \\
-\end{array}$ & $\begin{array}{l}-4,983 \\
-2,111 \\
-4,505 \\
-1,259 \\
-\end{array}$ & $\begin{array}{l}-0,392 \\
-0,528 \\
-0,430 \\
-0,662 \\
-\end{array}$ & $\begin{array}{l}-32,43 \\
-41,02 \\
-34,95 \\
-48,42 \\
-\end{array}$ & $\begin{array}{l}-2,865 \\
-5,006 \\
-3,924 \\
-4,315 \\
-\end{array}$ & $\begin{array}{l}-0,539 \\
-0,393 \\
-0,232 \\
-0,515 \\
-\end{array}$ & $\begin{array}{l}-41,67 \\
-32,50 \\
-20,71 \\
-40,25 \\
-\end{array}$ & $\begin{array}{l}-4,921 \\
-4,258 \\
-1,739 \\
-3,256 \\
-\end{array}$ \\
\hline \multicolumn{10}{|l|}{ Fibra textil: } \\
\hline 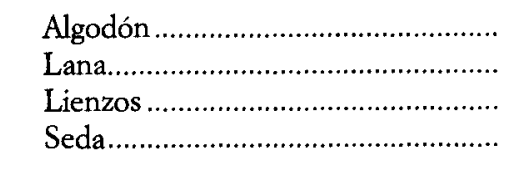 & $\begin{array}{l}0,259 \\
\mathbf{0 , 3 3 5} \\
\overline{\mathbf{0 , 5 0 8}}\end{array}$ & $\begin{array}{l}29,56 \\
39,79 \\
- \\
66,20\end{array}$ & $\begin{array}{l}0,853 \\
4,403 \\
\frac{-}{2,810}\end{array}$ & $\begin{array}{l}0,443 \\
0,604 \\
\overline{0,685}\end{array}$ & $\begin{array}{l}55,74 \\
82,94 \\
\overline{98,38}\end{array}$ & $\begin{array}{l}3,696 \\
6,689 \\
- \\
4,567\end{array}$ & $\begin{array}{l}\mathbf{0 , 2 4 2} \\
\mathbf{0 , 5 5 1} \\
- \\
0,137\end{array}$ & $\begin{array}{l}27,38 \\
73,50 \\
- \\
14,68\end{array}$ & $\begin{array}{l}2,060 \\
6,274 \\
- \\
0,709\end{array}$ \\
\hline \multicolumn{10}{|l|}{ Estado: } \\
\hline $\begin{array}{l}\text { Bueno } \\
\text { Usado } \\
\text { Viejo }\end{array}$ & $\begin{array}{c}- \\
-0,652 \\
-1,387\end{array}$ & $\begin{array}{l}-\overline{47,90} \\
-75,02\end{array}$ & $\begin{array}{r}- \\
-8,979 \\
-18,137\end{array}$ & $\begin{array}{l}-\overline{0,721} \\
-1,512\end{array}$ & $\begin{array}{l}- \\
-51,37 \\
-77,95\end{array}$ & $\begin{array}{r}- \\
-7,891 \\
-18,057\end{array}$ & $\begin{array}{l}-\overline{0} \\
-0,775 \\
-1,646\end{array}$ & $\begin{array}{l}-\overline{-} \\
-53,93 \\
-80,72\end{array}$ & $\begin{array}{r}-\overline{1} \\
-8,124 \\
-17,194\end{array}$ \\
\hline
\end{tabular}


Factores determinantes de la calidad de los textiles

Variable dependiente: valor o precio de los artículos textiles en reales

\begin{tabular}{|c|c|c|c|c|c|c|c|c|c|}
\hline \multirow[b]{2}{*}{ Variables explicativas } & \multicolumn{3}{|c|}{$1752-1765$} & \multicolumn{3}{|c|}{$1785-1800$} & \multicolumn{3}{|c|}{$1830-1840$} \\
\hline & Coeficiente & $\begin{array}{c}\text { Efecto } \\
\text { implicito } \\
\%\end{array}$ & $t$-student & Coeficiente & $\begin{array}{c}\text { Efecto } \\
\text { implicito } \\
\%\end{array}$ & $t$-student & Coeficiente & $\begin{array}{c}\text { Efecto } \\
\text { implicito } \\
\%\end{array}$ & t-student \\
\hline \multicolumn{10}{|l|}{ Gama: } \\
\hline 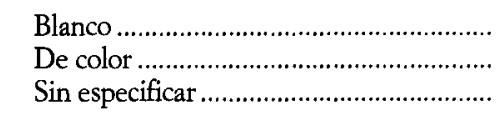 & $\begin{array}{c}-0,143 \\
\mathbf{0 , 1 9 1} \\
-\end{array}$ & $\begin{array}{c}-13,32 \\
21,05 \\
-\end{array}$ & $\begin{array}{c}-1,392 \\
2,616 \\
-\end{array}$ & $\begin{array}{r}-0,755 \\
0,074 \\
-\end{array}$ & $\begin{array}{c}-53,00 \\
7,68 \\
-\end{array}$ & $\begin{array}{r}-2,459 \\
0,785 \\
-\end{array}$ & $\begin{array}{r}0,302 \\
-0,022 \\
-\end{array}$ & $\begin{array}{c}35,26 \\
-2,18 \\
-\end{array}$ & $\begin{array}{r}0,703 \\
-0,210 \\
-\end{array}$ \\
\hline \multicolumn{10}{|l|}{ Origen: } \\
\hline 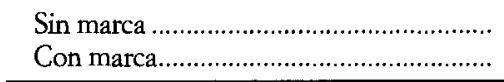 & $\overline{0,475}$ & $\overline{60,80}$ & $\overline{4,523}$ & $\overline{0,206}$ & $\overline{22,88}$ & $\overline{1,388}$ & $\overline{0,206}$ & $\overline{22,88}$ & $\overline{1,300}$ \\
\hline 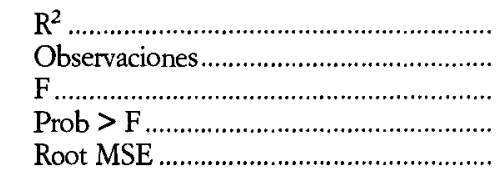 & & $\begin{array}{l}0,4136 \\
677 \\
39,48 \\
-\overline{-} \\
0,78253\end{array}$ & ' & & $\begin{array}{l}0,4777 \\
501 \\
38,73 \\
\overline{-} \\
0,78543\end{array}$ & & & $\begin{array}{l}0,4814 \\
436 \\
35,52 \\
- \\
0,79114\end{array}$ & \\
\hline
\end{tabular}

* Las variables referidas a la ubicación geográfica del artículo textil, a la fibra textil utilizada en la confección del tejido, al estado en que se encuentra el producto, a la gama de colores y al origen del producto son variables dummy o ficticias; de ahí que para evitar multicolinealidad perfecta una de las características (Palencia, Lienzos, Sin especificar y Sin marca, respectivamente) sea siempre eliminada.

$* *$ En negrita figuran los coeficientes que son significativos al 95 por 100 . 
varias categorias y se refleja, por tanto, en variables ficticias, cada estimación â serviría para estimar el porcentaje de variación sobre el precio de la presencia de ese atributo con respecto a la categoría de referencia (la categoría definida por los valores 0 de las ficticias). Así, por ejemplo, el hecho de que un artículo textil proceda de Aguilar o de Tierra de Campos supondría un aumento o una disminución estimada del precio en un porcentaje determinado sobre el correspondiente a un producto procedente de la capital palentina ${ }^{20}$.

Dado el valor de los coeficientes correspondientes a las variables geográficas, observamos, en primer lugar, que la calidad de los productos textiles era más alta en aquellos lugares que tenían una mayor apertura hacia el mercado (Palencia y Tierra de Campos). En este sentido, los productos textiles demandados en el campo eran entre un 20 por 100 y un 40 por 100 más baratos que los consumidos en la ciudad. Las razones de este hecho son complejas. Por un lado, siempre existe la posibilidad de criterios dispares entre los distintos notarios; por otra parte, cabe que estemos ante diferencias muy acusadas en los niveles de renta correspondientes a las zonas urbanas y rurales. Asimismo, es evidente que la amplitud de las redes de comercialización y distribución en las zonas urbanas, o en su defecto en las zonas próximas a las mismas, facilitó a las economías familiares la adquisición de productos de mayor calidad. En este contexto, también resulta obvio que el acceso al consumo de manufacturas textiles de mayor calidad por las capas populares resultaba bastante complicado hasta que no se produjese un abaratamiento sustancial de los productos, una mejora de las redes de comercialización o una mejora en su poder adquisitivo.

Por lo que respeta a la fibra textil utilizada, vemos que los productos textiles de más calidad eran aquellos que se confeccionaban con seda, lana y algodón. En 1830-1840 se produce una caída - aunque no sea significativa estadísticamente- muy apreciable en los productos de seda en relación con la lana y el algodón. También se aprecia que la utilización de los lienzos de lino no implicaba en la mayoría de los casos un precio demasiado elevado para la pieza textil. En otro orden de cosas, tampoco sorprende que las prendas de colores fueran más caras, así como aquellas en las cuales se especificaba su procedencia u origen, claro antecedente de las modernas marcas comerciales (Astudillo, Tarrasa o Segovia, por citar algunas). No obstante, conviene mantener cierta cautela, dada la poca sig-

${ }^{20}$ Si la variable fuera de tipo continuo (no cualitativa), el efecto implícito hace referencia al impacto porcentual en el precio del textil como consecuencia de incrementar la variable en una unidad. 
nificación estadística de las variables relativas a la gama de colores y al origen de los textiles ${ }^{21}$.

Por último, es evidente la asociación positiva que se puede establecer entre los productos nuevos (viejos) y su calidad, constatada a través de un precio más elevado. En este sentido, recordemos cuando afirmaba anteriormente que la variable viejo había disminuido o se había mantenido porque probablemente los textiles se desechaban con mayor rapidez, se ve ratificado ahora por el hecho de que entre 1752-1765 y $1830-1840$ aumenta la correlación negativa entre la variable viejo y la calidad del producto, pasando del 75 por 100 al 81 por 100 , lo cual quiere decir que un textil viejo era entre un 75 y un 81 por 100 más barato que un textil en perfectas condiciones. Es decir, el ritmo de reposición de los artículos textiles fue creciendo lenta pero progresivamente entre 1750 y 1840 , con lo que obviamente una parte importante del consumo de textiles se hizo a partir de piezas nuevas.

\section{LA EVOLUCIÓN DE LOS PRECIOS TEXTILES Y SU INFLUENCIA EN EL CONSUMO}

¿Cuáles fueron los estímulos que llevaron a las economías familiares a incrementar su consumo de textiles e incluso a modificar sus pautas de consumo? Obviamente las respuestas no pueden centrarse en una única dirección y así debería hablar de cambios en la oferta, en las redes de distribución y comercialización, en los niveles de renta, en los ingresos familiares y en los procesos de urbanización ${ }^{22}$, sin olvidar

\footnotetext{
${ }^{21}$ Habría que evaluar más detalladamente los progresivos cambios de índole técnica que se produjeron en el tratamiento de los tintes durante el primer tercio del siglo xIX. Estos cambios fueron especialmente significativos desde la década de 1820 en Sabadell, Tarrasa y Alcoy. Dichos cambios parecen lógicos tras la crisis del Antiguo Régimen y más si tenemos en cuenta la reducción de las importaciones españolas de añil y palo brasilete/campeche -que la manufactura alcoyana y catalana venían utilizando desde el siglo anterior- a una quinta y a una duodécima parte, respectivamente. Véase Fontana (1970), pp. 3-23. Muy probablemente estos cambios en el tinte explicarian la no relevancia estadística de la variable gama, o dicho de otra forma, el por qué en 1830-1840 el color de los textiles tenía una influencia pequeña en el precio final.

${ }^{22}$ En este punto he estimado un modelo econométrico que explicita el gasto en textiles -medido a través del valor del stock de textiles inventariado - como función de la riqueza, el volumen de ingresos anuales y dos variables dummies introducidas de forma aditiva: grado de urbanización y profesión del cabeza de familia. Dichas variables estarían expresadas en logaritmos, a excepción de las variables ficticias, siendo el método de estimación propuesto el de los mínimos cuadrados ordinarios. En dicha estimación $\operatorname{los} \mathrm{R}^{2}$ que he obtenido van
} 
el papel desempeñado por la renta de la tierra, dado el peso de la clase arrendataria y la evolución de los salarios reales y el coste de la vida ${ }^{23}$. Igualmente no se pueden desligar los aspectos económicos de los aspectos sociales a la hora de analizar los cambios en las pautas de consumo textil. La demanda de textiles no sólo depende del poder adquisitivo, sino también de las transformaciones en las formas de vida que se estaban produciendo al pasar de una sociedad estamental a una sociedad clasista. Teniendo en cuenta estas premisas, en este epígrafe voy a centrarme únicamente en la evolución de los precios en los artículos textiles con el fin de averiguar sus consecuencias económicas y sus efectos sobre el consumo.

Dada la importancia que el estado de conservación de los bienes textiles tiene en la calidad de los mismos, he recogido el precio medio de los artículos nuevos, desestimando el precio de los artículos viejos, usados o de aquellos otros en los cuales no se indique su estado de conservación. Esto, aunque ha reducido el tamaño de las observaciones disponibles,

desde 0,55 a mediados del siglo xvm hasta 0,65 en 1830-1840, resultando todos los regresores significativos. Asimismo, la elasticidad renta (coeficiente de la riqueza) de la demanda de textiles es relativamente estable en el tiempo, oscilando entre 0,582 para el período 1752-1765 y 0,608 para 1830-1840, lo cual significa, por ejemplo, que para un incremento del 1 por 100 en la riqueza de las familias a mediados del siglo Xx, la demanda de textiles aumentaría aproximadamente un 0,6 por 100 . Por lo que respecta a la renta disponible -medida a través del volumen de ingresos de anuales - su elasticidad es inferior a la de la riqueza, lo cual implica que aunque la renta disponible disminuyese el consumo de textiles no se alteraba sobremanera. En cuanto a la interpretación de los coeficientes de las variables cualitativas se puede afirmar, preservando la hipótesis ceteris paribus, que el gasto medio en textiles fue mucho más elevado para aquellas economías en las cuales la profesión del cabeza de familia se inscribía en el sector secundario o terciario, que si, por el contrario, se orientaba hacia la agricultura o la ganadería. Igualmente el gasto textil era bastante más alto en las familias que vivían en las zonas urbanas. Véase una formulación e interpretación más exhaustiva en Ramos (2001b), capítulo 5, pp. 204-232.

${ }^{23}$ Según recoge Llopis (2002), pp. 23-24, entre 1815 y 1830 los salarios reales en Cataluña, Navarra y Palencia fueron más elevados que en las tres décadas precedentes. De hecho, todas las series de precios analizadas por este autor, excepto la correspondiente a la Cataluña interior, alcanzaron sus valores máximos en los años veinte del siglo XIX. En la década siguiente, los salarios disminuyeron de manera muy heterogénea: pequeña en Navarra, moderada en Cataluña y fuerte en Palencia. Igualmente, Serrano (1999), p. 271, afirma que los salarios reales en Valladolid aumentaron entre 1814 y 1822, para caer paulatinamente desde entonces o como mucho mantenerse. En definitiva, para Moreno (2002), pp. $105-106$ «entre 1780 y 1860 los asalariados castellanos, en el mejor de los casos, no experimentaron incrementos significativos en sus ingresos reales; es más, la pérdida de bienestar que sufrieron a lo largo del segundo tercio del xx es incontrovertible [...]. En suma, el modelo de crecimiento económico castellano sirvió para equiparar los niveles de bienestar de las clases medias con el que éstas disfrutaban en los países más avanzados, pero a costa de arrumbar a los campesinos». 
ha permitido homogeneizar los artículos textiles en función de su calidad. Por otra parte, dada la gran variedad de productos textiles en las prendas exteriores e interiores, la incoherencia de algunos datos relativos a la ropa del hogar y la falta de los mismos en los textiles de decoración (cortinas), amén de la gran variedad de tejidos utilizados en la composición, ha implicado que me decante por aquellos artículos más abundantes en los inventarios post mortem y más homogéneos en la utilización de una fibra determinada. En consecuencia, los artículos elegidos han sido los calzones, las camisas, los jergones, las mantas y las sábanas. Estos artículos textiles cuentan con la ventaja adicional de poseer una desviación estándar relativamente pequeña; es decir, los precios de los artículos textiles están bastante próximos a la media, lo cual reduce significativamente el margen de error. Los precios medios en reales, distinguiendo entre entornos urbanos y rurales, han quedado reflejados en el cuadro 7 donde sobresalen ciertas diferencias entre ambos núcleos. En concreto, mientras el precio medio de las camisas, los jergones y las mantas tienden a converger en la ciudad y el campo hacia 1830-1840, lo cual sería síntoma inequívoco de la paulatina integración del mercado interior; sorprende, sin embargo, las fuertes discrepancias de precio entre campo y ciudad, a favor de esta última, en productos relativamente homogéneos (estado de conservación y misma fibra) como los calzones y las sábanas. No obstante, cuando nos referimos a precios medios en términos globales las diferencias no son tan acusadas; de hecho, apenas exceden los cinco reales entre 1750 y 1840 .

A partir de estas premisas he utilizado distintos índices de precios: Laspeyres, Paasche y Fisher. El índice de precios Laspeyres consiste en la media aritmética ponderada de los índices simples de precios, siendo el criterio de ponderación el valor de la cantidad consumida del bien i-ésimo en el período base a precios de dicho período. La elaboración de un índice de Laspeyres tiene la ventaja de que las ponderaciones del período base se mantienen fijas para todos los períodos. Sin embargo, presenta el inconveniente de que pierde representatividad a medida que nos alejamos del período base. Por tanto, se puede utilizar un índice de precios Paasche que calcula las ponderaciones para cada período corriente. Esto implica que el índice de precios de cada año se compara con el del año base, debido a que las ponderaciones varían de período en período, siendo, por consiguiente, distintas en los diferentes índices. Por esta razón, en la actualidad la mayoría de los índices de precios al consumo utilizados son de 
CUADRO 7

Precios medios de los artículos textiles en Palencia, 1750-1850 (en reales corrientes)

\begin{tabular}{|c|c|c|c|c|c|c|c|c|c|c|c|c|c|c|c|}
\hline \multirow[b]{2}{*}{ Articulo textil } & \multicolumn{5}{|c|}{$1752-1765$} & \multicolumn{5}{|c|}{$1785-1800$} & \multicolumn{5}{|c|}{$1830-1840$} \\
\hline & $\begin{array}{l}\text { Precio } \\
\text { medio }\end{array}$ & $\begin{array}{c}\text { Precio } \\
\text { máximo }\end{array}$ & $\begin{array}{c}\text { Precio } \\
\text { minimo }\end{array}$ & $\begin{array}{l}\text { Desviación } \\
\text { estándar }\end{array}$ & Muestra & $\begin{array}{l}\text { Precio } \\
\text { medio }\end{array}$ & $\begin{array}{c}\text { Precio } \\
\text { máximo }\end{array}$ & $\begin{array}{l}\text { Precio } \\
\text { minimo }\end{array}$ & $\begin{array}{l}\text { Desviación } \\
\text { eständar }\end{array}$ & Muestra & $\begin{array}{l}\text { Precio } \\
\text { medio }\end{array}$ & $\begin{array}{l}\text { Precio } \\
\text { máximo }\end{array}$ & $\begin{array}{c}\text { Precio } \\
\text { minimo }\end{array}$ & $\begin{array}{l}\text { Desviación } \\
\text { eständar }\end{array}$ & Muestra \\
\hline \multicolumn{16}{|l|}{ Ciudad: } \\
\hline 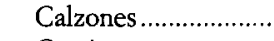 & 45,40 & 60 & 30 & 13,81 & 5 & 46,29 & 70 & 24 & 15,34 & 7 & 35,00 & 40 & 30 & 7,07 & 2 \\
\hline Camisa............................. & 16,00 & 24 & 12 & 4,58 & 11 & 19,60 & 30 & 16 & 4,97 & 10 & 16,67 & 24 & 10 & 5,10 & 9 \\
\hline Jergón ................................ & 22,45 & 33 & 12 & 6,28 & 11 & 27,10 & 40 & 13 & 7,03 & 20 & 20,00 & 34 & 16 & 6,43 & 7 \\
\hline Manta ............................. & 41,40 & 100 & 16 & 22,76 & 10 & 34,57 & 60 & 6 & 13,54 & 14 & 32,17 & 80 & 14 & 18,18 & 12 \\
\hline 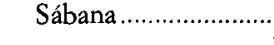 & 26,55 & 40 & 20 & 6,00 & 9 & 40,29 & 54 & 30 & 6,82 & 14 & 32,29 & 60 & 12 & 15,29 & 7 \\
\hline Precio medio total......... & 28,33 & - & - & 16,03 & 46 & 32,46 & - & 一 & 12,53 & 65 & 26,27 & - & - & 14,41 & 37 \\
\hline \multicolumn{16}{|l|}{ Campo: } \\
\hline Calzones .......................... & 17,47 & 30 & 10 & 5,84 & 15 & 22,75 & 72 & 7 & 21,14 & 8 & 18,75 & 32 & 8 & 8,71 & 12 \\
\hline Camisa ........................... & 11,56 & 18 & 8 & 2,91 & 17 & 14,45 & 24 & 8 & 4,95 & 11 & 15,13 & 30 & 8 & 5,30 & 16 \\
\hline Jergón ............................... & 20,09 & 27 & 14 & 3,74 & 16 & 28,63 & 40 & 20 & 7,03 & 8 & 20,00 & 30 & 16 & 5,80 & 6 \\
\hline Manta ........................... & 30,71 & 60 & 14 & 10,67 & 49 & 32,46 & 60 & 14 & 13,99 & 24 & 28,32 & 70 & 12 & 13,40 & 34 \\
\hline 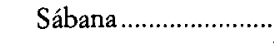 & 23,73 & 40 & 12 & 7,73 & 20 & 29,53 & 54 & 10 & 14,77 & 17 & 21,73 & 36 & 10 & 8,68 & 22 \\
\hline Precio medio total......... & 23,59 & 一 & 一 & 10,64 & 117 & 27,22 & - & - & 14,67 & 68 & 22,53 & 一 & - & 11,21 & 90 \\
\hline \multicolumn{16}{|l|}{ Agregado: } \\
\hline Calzones ......................... & 24,45 & 60 & 10 & 14,81 & 20 & 33,73 & 72 & 7 & 21,73 & 15 & 21,07 & 40 & 8 & 10,14 & 14 \\
\hline Camisa.............................. & 13,30 & 24 & 8 & 4,21 & 28 & 16,90 & 30 & 8 & 5,50 & 21 & 15,68 & 30 & 8 & 5,18 & 25 \\
\hline 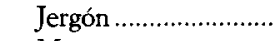 & 21,06 & 33 & 12 & 4,97 & 27 & 27,54 & 40 & 13 & 6,93 & 28 & 20,00 & 34 & 16 & 5,89 & 13 \\
\hline Manta ............................. & 32,53 & 100 & 14 & 13,82 & 59 & 33,24 & 60 & 6 & 13,68 & 38 & 29,33 & 80 & 12 & 14,68 & 46 \\
\hline 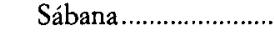 & 24,60 & 40 & 12 & 7,25 & 29 & 34,39 & 54 & 10 & 12,89 & 31 & 24,28 & 60 & 10 & 11,30 & 29 \\
\hline Precio medio total......... & 24,92 & - & - & 12,53 & 163 & 29,78 & - & - & 13,87 & 133 & 23,62 & - & - & 12,29 & 127 \\
\hline
\end{tabular}

FUENTE: Archivo Histórico Provincial de Palencia. Véase Bibliografía. 
Laspeyres. Finalmente, el índice de Fisher consiste en la media geométrica de los índices de precios Laspeyres y Paasche ${ }^{24}$.

Los primeros resultados -véase cuadro 8- ponen de relieve que el alza de los precios textiles fue un fenómeno general a finales del siglo XVII (incremento entre 1752-1765 y 1785-1700), mientras que a partir del siglo XIX (entre 1785-1700 y 1830-1840) los precios textiles comenzaron a descender en relación con la tónica de período anterior. Igualmente, sabemos que, al margen de que subieran o bajaran los precios textiles, entre 1750 y 1840 se produjo un aumento en el consumo de textiles. ¿Cuáles son las razones que explican este hecho? En principio podemos tener dos. Por un lado, la coyuntura económica del período y, por otro, la evolución de los precios relativos o la relación de intercambio entre los precios textiles y agrarios.

Con respecto a la primera cuestión se observa que los precios textiles siguen la misma dinámica que los precios del trigo en Medina de Rioseco (Valladolid), los índices del coste de la vida en Palencia y en Valladolid y el índice Reher-Ballesteros que recoge precios para Castilla La Nueva

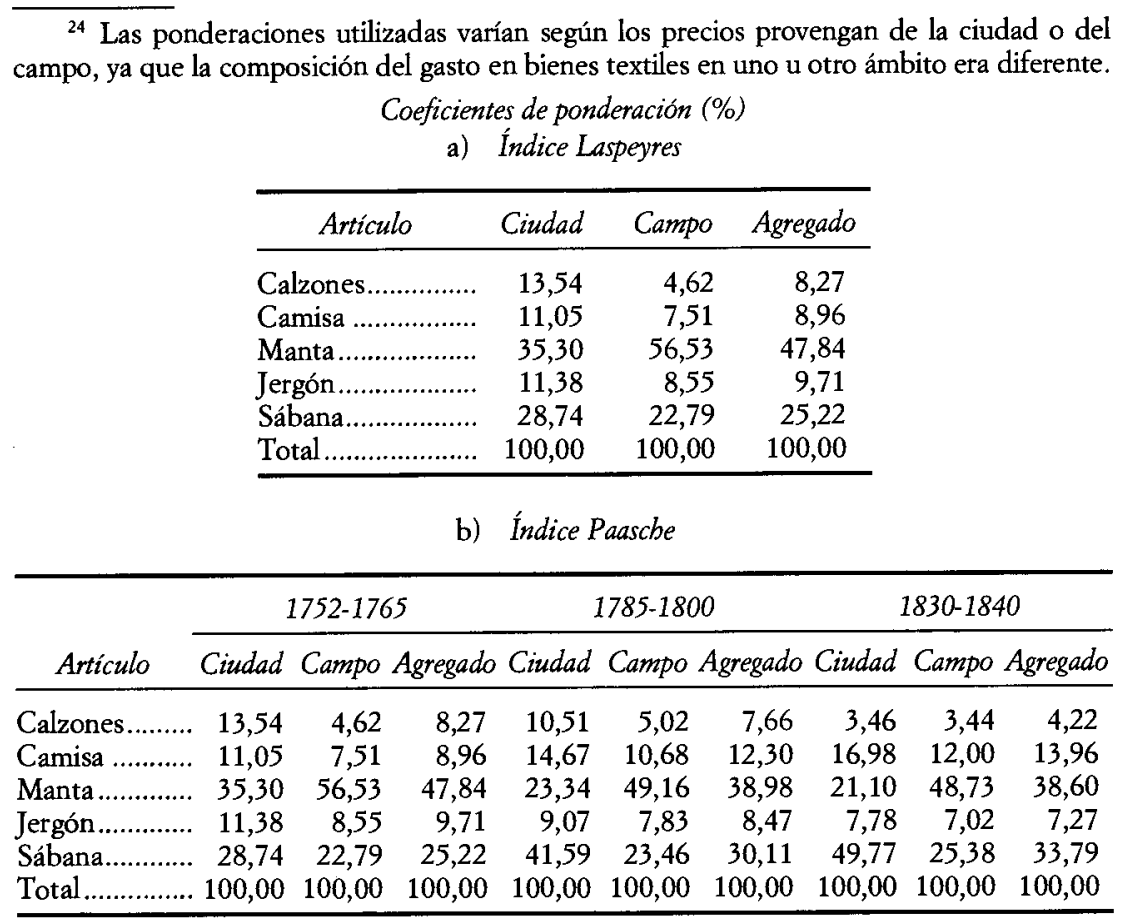




\section{CUADRO 8}

Evolución de los precios textiles en Palencia, 1750-1850 Base 100: 1752-1765

\begin{tabular}{|c|c|c|c|c|c|c|c|c|c|}
\hline \multirow{2}{*}{ Índice de precios textiles } & \multicolumn{3}{|c|}{$1752-1765$} & \multicolumn{3}{|c|}{$1785-1800$} & \multicolumn{3}{|c|}{$1830-1840$} \\
\hline & Ciudad & Campo & Agregado & Ciudad & Campo & Agregado & Ciudad & Campo & Agregado \\
\hline Laspeyres & 100 & 100 & 100 & 123,06 & 133,36 & 130,53 & 97,19 & 99,82 & 96,77 \\
\hline 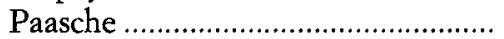 & 100 & 100 & 100 & 127,54 & 127,41 & 127,92 & 105,73 & 97,62 & 96,65 \\
\hline Fisher & 100 & 100 & 100 & 125,28 & 130,35 & 129,22 & 101,37 & 98,71 & 96,71 \\
\hline Precios del trigo en Medina de Rio- & & & & & & & & & \\
\hline $\operatorname{seco}(1)$. & n.d. & n.d. & 100 & n.d. & n.d. & 177,41 & n.d. & n.d. & 137,83 \\
\hline Indice de precios en Palencia (2) ..... & n.d. & n.d. & 100 & n.d. & n.d. & 152,80 & n.d. & n.d. & 149,90 \\
\hline Coste de la vida en Valladolid (3) .... & n.d. & n.d. & 100 & n.d. & n.d. & 144,84 & n.d. & n.d. & 143,61 \\
\hline Reher-Ballesteros (4) ............................ & n.d. & n.d. & 100 & n.d. & n.d. & 149,15 & n.d. & n.d. & 143,56 \\
\hline
\end{tabular}

Notas: (1) Sobre los precios del trigo en Medina de Rioseco (Valladolid) he utilizado como base 100 el período 1752-1765. Datos facilitados por los profesores Barquín y Yun.

(2) Moreno (2002), pp. 108-110.

(3) Serrano (1999), p. 265. Los datos empiezan en 1760, de ahí que para los años en que no tenemos referencias hayamos utilizado el índice 100.

(4) Reher-Ballesteros (1993), pp. 134-135. 
(fundamentalmente en Madrid). Las razones de esto han sido ampliamente documentadas por la historiografía especializada ${ }^{25}$. Como es bien sabido, el aumento de la producción agrícola en el siglo xvm fue lento y no se debió a mejoras en la productividad, sino que estuvo basado en el aumento de la tierra cultivada y, por tanto, sujeto a rendimientos por superficie decrecientes a medida que se avanzaba en el cultivo de tierras de peor calidad. En este contexto, una mayor producción acabaría implicando indefectiblemente, más tarde o más temprano, un incremento en los precios agrícolas, lo cual serviría de estímulo para elevar la renta de la tierra. Al mismo tiempo, la población palentina crecía moderadamente, lo cual repercutió positivamente sobre su industria textil ${ }^{26}$. Sin embargo, este crecimiento de la industria textil fue consecuencia del alza de los precios de los productos industriales demandados por las economías familiares con un nivel de vida medio-alto. De ahí que el alza de la renta, el endeudamiento progresivo de las economías familiares y la caída de los salarios obligase a muchas familias campesinas de la provincia palentina a dirigir su esfuerzo productivo hacia actividades auxiliares (industria textil de lanas bastas y lienzos) que a su vez trascendía en un mayor consumo de textiles por familia, y, por ende, en un mayor precio de los textiles. Durante el siglo XIX se observa, una vez finalizada la Guerra contra Francia y la pérdida de las colonias americanas, un proceso de reconversión en las manufacturas - lanas finas y algodones catalanes, sedas valencianas y lienzos gallegos- ${ }^{27}$ de las regiones en vías de mecanización que incentivaron la producción y la extensión de las redes comerciales en toda la península, lo cual incidía, a su vez, en un menor precio de los textiles.

La segunda razón tiene que ver con la evolución de la relación de intercambio entre los precios de las manufacturas textiles y los precios (1987).

${ }^{25}$ Las siguientes líneas se basan en García Sanz (1977 y 1985), Marcos (1985) y Yun

${ }^{26}$ Las vicisitudes de la industria textil palentina entre 1750 y 1900 son bien conocidas. Recordemos que el período $1750-1800$ se caracterizaba por una relativa expansión de la industria textil urbana (donde sobresalía el importante Gremio de la Puebla dedicado a la fabricación de bayetas y cobertores o mantas) y rural. Desde 1800 a 1830 se asiste a una importante crisis de la industria textil palentina, para recuperarse parcialmente, aunque sin llegar a los niveles de años anteriores, en 1830-1840 debido a la especialización productiva en mantas. A partir de 1850 comienza el proceso de transición hacia un moderno sistema fabril que, no obstante, todavía no dará sus primeros pasos hasta la década de 1880. García Colmenares (1992).

${ }^{27}$ En el caso catalán, véase Nadal (1991), pp. 13-85, y Benaul (1991), pp. 86-157; para Valencia, Franch (1986), pp. 75-107 y 297-305, y para los lienzos gallegos, Carmona (1990). 
agrarios. Para ello utilizo como deflactores los precios del trigo en Medina de Rioseco y el índice del coste de la vida en Palencia. La construcción de los correspondientes índices de Laspeyres, Paasche y Fisher señalan que cuando los precios de las manufacturas textiles subieron en 1785-1800 lo hicieron en menor cuantía que los precios agrarios o el coste de la vida. Asimismo, cuando el precio del textil disminuyó durante el siglo XIX se correspondía, a su vez, con una caída mayor de los precios agrarios (fundamentalmente del trigo). En efecto, en el cuadro 9 se aprecia esta disminución en la relación de intercambio entre los precios de las manufacturas textiles y los precios agrícolas ${ }^{28}$ que, combinada con un aumento en los ritmos de reposición de los bienes textiles y un cierto desarrollo del sentido de lo doméstico, permitieron destinar una mayor proporción del presupuesto familiar a artículos textiles de tipo industrial y a otros bienes de carácter duradero y semiduradero.

Ahora bien, ¿por qué variaron los precios relativos? Conviene recordar que los precios relativos pueden modificarse por cambios en la productividad de los factores y por cambios demográficos (aunque el tamaño de la población por sí solo no explica el aumento en los precios). De hecho, las variaciones en los precios relativos reflejan la existencia de elasticidades (renta y precio) de oferta y demanda distintas en cada uno de los sectores. Es decir, la respuesta del sector agrario y del sector textil al crecimiento demográfico fue distinta según las características de las funciones de demanda y la tecnología empleada en la función de producción correspondiente. En este sentido, Garrabou y Sanz han constatado que el incremento de la producción agraria se produjo sin innovaciones tecnológicas, o lo que es lo mismo, sin cambios en la función de producción ${ }^{29}$, mientras que el sector textil registró cambios significativos en la productividad de los factores. En este contexto, el concepto de revolución industriosa (productividad del trabajo) acuñado por De Vries ${ }^{30}$ y la progresiva mecanización (productividad del capital) experimentada en la industria textil durante el siglo XIX ayudan a entender mejor estos cambios. Tampoco

${ }^{28}$ Este hecho vendría a coincidir con lo que Yun (1995a), pp. 212-213, ha observado con la relación entre los precios del trigo y de otros productos procedentes de regiones cercanas, como el lienzo gallego, la cual se mantuvo más o menos uniforme entre 1730 y 1770 , mientras que, sin embargo, desde 1780 hasta 1810 la relación se fue incrementando paulatinamente, lo cual explicaría el aumento del consumo textil que se produjo a finales del siglo xvII. En el plano internacional, Shammas (1990), pp. 96-100, ha constatado exactamente la misma evolución de los precios relativos para Inglaterra.

${ }^{29}$ Garrabou y Sanz (1985).

${ }^{30}$ De Vries (1993), pp. 85-132. 
Evolución de los precios relativos en Palencia, 1750-1850

$$
\text { Base 100: 1752-1765 }
$$

a) Deflactor: Precios del trigo en Medina de Rioseco (Valladolid)

\begin{tabular}{|c|c|c|c|c|c|c|c|c|c|}
\hline \multirow{2}{*}{ Índice de precios } & \multicolumn{3}{|c|}{$1752-1765$} & \multicolumn{3}{|c|}{$1785-1800$} & \multicolumn{3}{|c|}{$1830-1840$} \\
\hline & Ciudad & Campo & Agregado & Ciudad & Campo & Agregado & Ciudad & Campo & Agregado \\
\hline 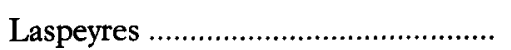 & 100 & 100 & 100 & 69,11 & 74,47 & 76,49 & 56,38 & 83,53 & 68,96 \\
\hline 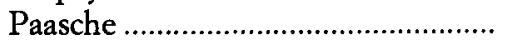 & 100 & 100 & 100 & 67,02 & 71,23 & 73,66 & 54,24 & 80,70 & 67,06 \\
\hline 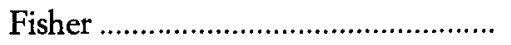 & 100 & 100 & 100 & 68,06 & 72,83 & 75,06 & 55,30 & 82,10 & 68,00 \\
\hline
\end{tabular}

b) Deflactor: Índice del Coste de la Vida en Palencia

\begin{tabular}{|c|c|c|c|c|c|c|c|c|c|}
\hline \multirow{2}{*}{ Indice de precios } & \multicolumn{3}{|c|}{$1752-1765$} & \multicolumn{3}{|c|}{$1785-1800$} & \multicolumn{3}{|c|}{$1830-1840$} \\
\hline & Ciudad & Campo & Agregado & Ciudad & Campo & Agregado & Ciudad & Campo & Agregado \\
\hline Laspeyres & 100 & 100 & 100 & 84,80 & 94,14 & 92,71 & 60,65 & 75,67 & 67,37 \\
\hline Paasche & 100 & 100 & 100 & 85,89 & 89,71 & 90,34 & 63,74 & 73,68 & 66,89 \\
\hline Fisher & 100 & 100 & 100 & 85,34 & 91,90 & 91,52 & 62,18 & 74,67 & 67,13 \\
\hline
\end{tabular}


debieran olvidarse las variaciones acaecidas en el nivel y distribución de la renta que sin lugar a dudas alteraron las pautas de consumo de la población, modificando la proporción del gasto que las familias destinaban a bienes agrícolas y productos textiles.

\section{CONCLUSIONES}

Los resultados aquí obtenidos muestran que entre 1750 y 1840 se produjo un aumento sostenido en el consumo de bienes textiles - ya fueran manufacturas urbanas de mayor calidad como productos provenientes de la industria rural a domicilio- por parte de las clases medias urbanas y rurales palentinas. Dicho incremento fue relativamente moderado aunque bastante significativo, dado el menor poder adquisitivo de las familias del interior y el relativo atraso de la economía castellana en comparación con otras zonas de la península. Además, esta expansión del consumo textil en Palencia coincide con una etapa de crecimiento generalizado en la economía castellana, con una recuperación de los salarios reales de albañiles y jornaleros palentinos entre 1815 y $1830^{31}$, y con una evolución favorable de las tasas de crecimiento vegetativo y mortalidad general durante el período $1810-1850^{32}$. Permítaseme enfatizar que en este incremento tuvo un papel decisivo la compra de artículos textiles nuevos y no sólo la adquisición de textiles de segunda mano. A su vez, en este crecimiento no se aprecian cambios sustanciales en la estructura del gasto textil, aunque sí la utilización cada vez más extendida de tejidos de algodón, con lo que este hecho significa en el proceso de industrialización español. Por otra parte, la evidencia empírica nos muestra que la relación de intercambio entre los precios de las manufacturas textiles y los precios agrarios o el coste de la vida

\footnotetext{
${ }^{31}$ Moreno (2002), pp. 75-112.

${ }^{32}$ Según García Colmenares (1998), p. 108, durante el siglo XXX los índices de mortalidad continúan siendo elevados aunque con notorias diferencias. Así, por ejemplo, durante la primera mitad del XIX se aprecian importantes oscilaciones que van desde el 80 por 1.000 de media durante la crisis de principios de siglo (1800-1804) hasta los bajos índices de las décadas siguientes (no llegan al 30 por 1.000 entre 1815 y 1829), si exceptuamos el repunte en 1830-1834 (51,2 por 1.000) debido a la epidemia de cólera de 1834. Por su parte, en la segunda mitad del siglo XIX no existen tales oscilaciones aunque los índices medios son elevados por encima del 40 por 1.000 en la ciudad. Con respecto a las tasas de crecimiento vegetativo -véase p. 122 - entre 1815 y 1830 hay un período de crecimiento demográfico positivo que se mueve entre 20 y 30 puntos, interrumpido por la epidemia de cólera mencionada anteriormente. Entre 1840 y 1854 se alcanzan nuevamente tasas de crecimiento vegetativas oscilando entre los 10 y 20 puntos. Finalmente, la provincia palentina experimentará tasas de crecimiento negativas desde 1865 hasta finales del siglo XIX.
} 
influyó positivamente en un mayor consumo textil. ¿Qué implicaciones se desprenden de estos resultados? Primero, el crecimiento de la propensión marginal al consumo de bienes textiles durante la época preindustrial vendría a matizar la responsabilidad de la demanda interior en el fracaso de la revolución industrial española. Segundo, este aumento en el consumo de bienes textiles nuevos, tanto en familias campesinas como urbanas, permite esbozar un panorama más optimista sobre los niveles de vida del que pudiera deducirse a partir de la evolución de otras variables económicas y sociales.

Este artículo también arroja luz sobre el debate historiográfico internacional relativo a por qué aumentó la demanda de textiles. En dicho debate existen de partida dos posturas contrapuestas. Por un lado, McKendrick sugiere que, a partir de la segunda mitad del siglo xvIII, se produjeron una serie de cambios en las pautas y hábitos de consumo de las economías familiares que incentivaron la producción de bienes manufacturados - básicamente textiles-y estimularon la Revolución Industrial inglesa ${ }^{33}$. Sin embargo, Mokyr se opone frontalmente a estos argumentos y enfatiza, por el contrario, la importancia de los cambios que tuvieron lugar en la oferta $^{34}$. Posteriormente, De Vries intenta reconciliar ambas posturas mediante el concepto de revolución industriosa o, si se quiere, tal como ha traducido Torras, revolución laboriosa. Brevemente, consistiría en la tendencia a trabajar cada vez más en el seno de las familias campesinas para reforzar sus vínculos con el mercado mediante la comercialización de los productos producidos por dichas familias con el fin de obtener ingresos adicionales que, a su vez, les permitieran acceder al consumo de manufacturas de mayor calidad que ellas mismas no podían producir ${ }^{35}$.

¿Qué aporta el caso de Palencia y por extensión de Castilla a este debate? En principio, la provincia palentina constituyó entre 1750 y 1850 un área de relativa importancia en el comercio del siglo xvIII, que estaba vinculada con economías de montaña y con la zona portuaria de Santander, lo cual estimuló el mercado, la formación de redes comerciales y un mayor dinamismo en las pautas de consumo ${ }^{36}$. Conocemos igualmente el desarrollo y el relativo éxito de la industria harinera y el establecimiento de una banca regional a mediados del siglo XIX. Sin embargo, también sabemos con absoluta certeza que la economía castellana, a diferencia de la catalana

\footnotetext{
${ }^{33}$ McKendrick (1982), pp. 9-33.

${ }_{34}$ Mokyr (1993), pp. 59-67.

${ }^{35}$ De Vries (1993), pp. 85-113, y (1994), pp. 249-271.

${ }^{36}$ Yun $(1995$ b) , p. 56.
} 
o de la vasca, no evolucionó en la segunda mitad del siglo Xxx hacia formas fabriles de organización en el sector textil. Además, en Castilla -según ha indicado García Sanz- se optará por realizar el tránsito hacia una sociedad industrial a partir del capitalismo agrario ${ }^{37}$. Por consiguiente, según explica Yun, las diferencias que se daban en el grado de desarrollo económico bien pudieran venir motivadas por el marco socio-económico en el cual se generaron esas presiones a producir más para el mercado ${ }^{38}$. Es decir, Castilla constituye un ejemplo de la revolución laboriosa enunciada por De Vries que, sin embargo, no acabó en un proceso de industrialización. ¿Por qué? Probablemente debido a que las posibilidades de una demanda sostenida de productos industriales en Castilla topaban con las fluctuaciones de las cosechas y de los precios del trigo, todavía importantes a pesar de los progresos en la formación del mercado interior español, y, sobre todo, con la excesiva concentración de la riqueza que limitaban la producción y el consumo ${ }^{39}$.

En definitiva, la clave estaría en la relación que se pudiera establecer entre las variaciones producidas en la renta familiar y los cambios en la demanda, la producción de manufacturas textiles y las redes de comercialización, sin olvidar el alcance de la urbanización, para establecer en términos económicos el grado de respuesta de la oferta a los cambios en la demanda agregada. A tenor de lo expuesto en este artículo, parece evidente que fueron la renta, el continuo paso de la población de una agricultura de subsistencia a una economía de mercado localizada preferentemente en las ciudades y la disminución de la relación de intercambio entre los precios de las manufacturas textiles y los precios agrícolas, los elementos básicos que generaron el crecimiento en la demanda de textiles.

\section{BIBLIOGRAFÍA}

Benaul, J. (1991): «La llana», en VVAA, Historia Económica de la Catalunya Contemporània, s. XIX, t. 3: Industria, transports i finances, pp. 86-157.

Borsay, P. (1989): The English Urban Renaissance. Culture and Society in the Provincial Town, 1660-1770, Oxford.

CARASA SOTO, P. (1987): Pauperismo y revolución burguesa (Burgos, 1750-1900), Valladolid, Junta de Castilla y León.

Carmona, J. (1990): El atraso industrial de Galicia. Auge y liquidación de las manufacturas textiles (1750-1900), Barcelona, Ariel.

\footnotetext{
${ }^{37}$ García Sanz (1991), pp. 19-46.

${ }^{38}$ Yun (1995b), p. 67.

39 Yun (1987), pp. 525-545.
} 
CERDÁ, I. [(1867) 1968]: «Monografía estadística de la clase obrera de Barcelona en 1856», Teoria General de la Urbanización y aplicación de sus principios y doctrinas a la Reforma y Ensanche de Barcelona, 3 vols., Madrid, Instituto de Estudios Fiscales.

Cropper, M. L.; Deck, L. B., y McConell, K. (1988): «On the Choice of Functional Forms for Hedonic Price Functions», en Review of Economics and Statistics, vol. 70, pp. 668-675.

Fine, B., y LEopold, E. (1993): The World of Consumption, New York, Routledge.

FonTANA, J. (1970): «Colapso y transformación del comercio exterior español entre 1792 y $1827 »$, en Moneda y Crédito, 115, pp. 3-23.

Franch Benavent, R. (1986): Crecimiento comercial y enriquecimiento burgués en la Valencia del siglo XVII, Valencia, Institució Alfons el Magnànim.

García Colmenares, P. (1992): Evolución y crisis de la industria textil castellana. Palencia, 1750-1990, Madrid, Mediterráneo.

García Sanz, A. (1977): Desarrollo y crisis del Antiguo Régimen en Castilla la Vieja. Economía y sociedad en tierras de Segovia, 1500-1814, Madrid, Akal.

- (1985): «El interior peninsular en el siglo xvin: un crecimiento moderado y tradicional», en R. FERNÁndEZ (ed.), España en el siglo XVIII. Homenaje a Pierre Vilar, Barcelona, Crítica, pp. 630-680.

- (1991): «Desarrollo del capitalismo agrario en Castilla y León en el siglo XIX. Algunos testimonios, algunas reflexiones y un epílogo», en B. YUN (coord.), Estudios sobre capitalismo agrario, crédito e industria en Castilla: siglos XIX-XX, Salamanca, Junta de Castilla y León, pp. 19-46.

García Simón, A. (1999): Castilla y León según la visión de los viajeros extranjeros. Siglos XV-XIX, Salamanca, Junta de Castilla y León.

GARRABOU, R., y GARCía SANZ, A. (1985): Historia agraria de la España contemporánea, t. I: Cambio social y nuevas formas de propiedad (1800-1850), Barcelona, Crítica.

Garrod, G., y Willis, K. (1993): «The Value of Waterside Properties: Estimating the Impact of Waterways and Canals on Property Values Through Hedonic Price Models and Contingent Valuation Methods», en Countryside Change Working Paper Series, núm. 44, University of Newcastle Upon Tyne.

GRIICHES, Z. (1971): Price Indexes and Quality Change, Cambridge Massachusetts, Harvard University Press.

INE (1994): Índice de Precios de Consumo Base 1992. Metodología, Madrid.

Hohenberg, P. M. (1993): The making of Urban Europe, 1000-1994, 2. ${ }^{2}$ ed., Cambridge Massachusetts, Harvard University.

LANCASTER, K. (1966): «A new approach to consumer theory», en Journal of Political Economy, vol. 74, pp. 132-157.

LE PlaY, F. (1990): Campesinos y pescadores en el Norte de España: tres monografías de familias trabajadoras a mediados del siglo XIX, Madrid, Ministerio de Agricultura, Pesca y Alimentación.

Liegey, P. (1993): «Adjusting Apparel Indexes in the Consumer Price Index for Quality Differences», en M. Foss, M. Manser y A. Young, Price Measurements and Their Uses, Chicago, The University of Chicago Press, pp. 209-226.

LLOPIS, E. (2002): «La agricultura, 1790-1840: de la crisis a la gran fiebre roturadora», Congreso Internacional 1802: España entre dos siglos y la devolución 
de Menorca, Sociedad Estatal de Conmemoraciones Culturales, Ciutadella de Menorca, 23-25 de septiembre de 2002.

Marcos, A. (1985): Economia, sociedad y pobreza en Castilla: Palencia, 1500-1814, 2 vols., Palencia, Diputación Provincial de Palencia.

Martínez Carrión, J. M. (2002) (ed.): El nivel de vida en la España rural, siglos XVIII-XX, Alicante, Universidad de Alicante.

MCKENDRICK, N. (1982): «The Consumer Revolution of Eighteenth-Century England», en N. MCKENDRICK, J. BREWER y J. H. PLuMB, The Birth of a Consumer Society. The commercialization of Eighteenth-Century England, London, Europa Publications Limited, pp. 9-33.

Mokrr, J. (ed.) (1993): The British Industrial Revolution. An Economic Perspective, London, Boulder.

MORENO, J. (2002): «¿'Fomentó el capitalismo agrario la desigualdad? Salarios y niveles de vida en Castilla la Vieja, 1751-1861», en J. M. MarTínez Carrión (ed.), El nivel de vida en la España rural, siglos XVII-XX, Alicante, Universidad de Alicante, pp. 75-112.

NADAL, J. (1991): «La industria cotonera», en VVAA, Història Económica de la Catalunya Contemporània, s. XIX, t. 3, Industria, transports i finances, pp. 13-85.

Ramos PalenCia, F. C. (2001a): «Pautas de consumo familiar en la Castilla preindustrial: Palencia, 1750-1850», en Revista de Historia Económica, año XIX, núm. extraordinario, pp. 37-59.

- (2001b): «Pautas de consumo familiar y mercado en la Castilla Preindustrial. $\mathrm{El}$ consumo de bienes duraderos y semiduraderos en Palencia, 1750-1850», Tesis doctoral, Facultad de CC Económicas y Empresariales, Universidad de Valladolid.

Rosen, S. (1974): «Hedonic Prices and Implicit Markets: Product Differentiation in Pure Competition», en Joumal of Political Economy, vol. 82, núm. 1, pp. 34-55.

SERRANO, R. (1999): «Los salarios reales en Valladolid, 1760-1875: Resultados e interrogantes», en J. TORRAS y B. YUN (eds.), Consumo, condiciones de vida y comercialización en Cataluña y Castilla, ss. XVII-XIX, Junta de Castilla y León, Consejería de Educación y Cultura, pp. 245-271.

Shammas, C. (1990): The Pre-industrial Consumer in England and America, Oxford, Clarendon Press.

SIMPSON, J. (1989): «La producción agraria y el consumo español en el siglo XIX», en Revista de Historia Económica, año VII, núm. 3, pp. 355-388.

TORRAS, J., y YUN, B. (1999) (eds.): Consumo, condiciones de vida y comercialización en Cataluña y Castilla, ss. XVII-XIX, Junta de Castilla y León, Consejería de Educación y Cultura.

VRIES, J. de (1993): «Between purchasing power and the world of goods: understanding the household economy in early modern Europe», en J. BREWER y R. Porter (eds.), Consumption and the World of Goods, London-New York, Routledge, pp. 85-132.

- (1994): «The Industrial Revolution and the Industrious Revolution», Journal of Economic History, 54, pp. 249-271.

WeATHERILL, L. (1988): Consumer Behaviour and material culture in Britain, 1660-1760, London-New York, Routledge. 
Yun, B. (1987): Sobre la transición al capitalismo en Castilla. Economía y Sociedad en Tierra de Campos (1500-1814), Salamanca, Junta de Castilla y León.

- (1991) (ed.): Estudios sobre capitalismo agrario, crédito e industria en Castilla: siglos XIX-XX, Salamanca, Junta de Castilla y León.

- (1995a): «El problema del capitalismo y su fracaso, Reflexiones sobre la historia económica de Castilla en la Época Moderna», en A. García Simón (ed.), Historia de una Cultura, Salamanca, Junta de Castilla y León, t. III, pp. 171-223.

- (1995b): «Perspectivas para la investigación en historia económica y social de Palencia: Consumo y redes de comercialización», Separata del Tomo III de las Actas del III Congreso de Historia de Palencia, pp. 51-68.

\section{FUENTES DOCUMENTALES}

\section{Archivo Histórico Provincial de Palencia (AHPP):}

Sección Protocolos Notariales:

Años 1752-1765:

Libros 97, 98, 99, 379, 433, 434, 435, 642, 643, 675, 1000, 2656, 2733, 3731, $3732,3793,3795,6277,6278,6962,6964,7814,7816,7817,10617,10618,10619$, 10834,11383 y 11384 .

Años 1785-1800:

Libros 107, 522, 523, 524, 525, 628, 629, 630, 653, 700, 731, 3065, 3066, $3165,3354,3356,6075,6076,6078,6082,6537,6538,6539,6540,6541,6542$, $7226,7343,7347,7461,7462,7463,7513,7515,7519,7733,7734,10605,11358$ y 11359.

Años 1830-1840:

Libros 360, 361, 376, 377, 378, 547, 1194, 1195, 1238, 1239, 3491, 3493, $3494,3495,3496,4440,6490,7256,7537,7538,7540,11987,11988,12847$, $12863,12869,12870,12871,12877$ y 12878.

Catastro de Ensenada: Respuestas Generales y Particulares. 